Article

\title{
Absorption Chillers to Improve the Performance of Small-Scale Biomethane Liquefaction Plants
}

\author{
Alessio Ciambellotti, Gianluca Pasini, Andrea Baccioli *(D), Lorenzo Ferrari (D) and Stefano Barsali \\ Dipartimento di Ingegneria dell'Energia, dei Sistemi, del Territorio e delle Costruzioni (DESTEC)— \\ Università di Pisa, 56122 Pisa, Italy; destec@pec.unipi.it or alessio.ciambellotti@phd.unipi.it (A.C.); \\ gianluca.pasini@for.unipi.it (G.P.); lorenzo.ferrari@unipi.it (L.F.); stefano.barsali@unipi.it (S.B.) \\ * Correspondence: andrea.baccioli@unipi.it
}

Citation: Ciambellotti, A.; Pasini, G.; Baccioli, A.; Ferrari, L.; Barsali, S. Absorption Chillers to Improve the Performance of Small-Scale Biomethane Liquefaction Plants. Energies 2022, 15, 92. https:// doi.org/10.3390/en15010092

Academic Editors: Lasse Rosendahl and Paul L. Chen

Received: 4 October 2021

Accepted: 10 December 2021

Published: 23 December 2021

Publisher's Note: MDPI stays neutral with regard to jurisdictional claims in published maps and institutional affiliations.

Copyright: (c) 2021 by the authors. Licensee MDPI, Basel, Switzerland. This article is an open access article distributed under the terms and conditions of the Creative Commons Attribution (CC BY) license (https:// creativecommons.org/licenses/by/ $4.0 /)$.

\begin{abstract}
Biomethane liquefaction may help decarbonization in heavy transportation and other hard-to-abate sectors. Small-scale liquefaction plants ( $<10$ ton/day) are suitable for small biogas plants located near farms and other agricultural activities. "Internal refrigerant" refrigeration cycles (e.g., Kapitza cycle) are often proposed for small-scale natural gas liquefaction due to their simplicity. An optimized Kapitza-based cycle is modeled and simulated, and then several modifications were studied to evaluate their influence on the energetic and economic performances. Results showed a specific consumption ranging between $0.65 \mathrm{kWh} / \mathrm{kg}$ and $0.54 \mathrm{kWh} / \mathrm{kg}$ of bio-LNG with no significant improvements by increasing cycle complexity. Instead, a reduction of $17 \%$ was achieved with the implementation of absorption chillers, that effectively turn waste heat into useful cooling energy. An economic assessment was finally carried showing that the Levelized Cost of Liquefation is more affected by electricity cost than additional CapEx.
\end{abstract}

Keywords: liquefaction; biomethane; gas liquefaction; absorption chiller; exergy analysis; economic analysis

\section{Introduction}

Biomethane is a renewable fuel produced by removing $\mathrm{CO}_{2}$ from biogas with a limited carbon footprint. This fuel can represent an interesting solution for several end-users, by helping to decarbonize energy production and mobility sectors. In addition, biomethane can be injected into gas grids to increase the green share of natural gas or liquefied [1] to be used in heavy-duty or marine mobility. The interest in liquefied biomethane has been rising in the last few years. In 2020 U.S. Trade and Development Agency (USTDA) has provided an 806,266 US\$ grant to fund a feasibility study for the building of a micro-scale plant in Mexico with a capacity of about 40 tons/day of LNG [2].

Biomethane is produced from biogas deriving from waste feedstocks such as the organic fraction of municipal solid waste and agricultural activities, or sewage from water treatment plants. Many European countries are fostering biogas production since it promotes the circular economy [3] and provides sanitation services by valorizing sewage and municipal organic waste [4]. Many authors studied the energy balance of biogas production evaluating the impact of feedstocks and production chain showing the strong influence of transportation distance and type of feedstocks [5]. Nowadays biogas is usually burned in internal combustion engines or gas turbines to produce electricity and heat [6] but recently the production of biomethane has been subsidized by many European countries being easily integrable with existent natural gas facilities [7]. In particular, the role of liquefied biomethane in the decarbonization of the heavy transport sector has been studied and confirmed [8]. Biogas may have different compositions based on the feedstock that has been involved in the digestion process and it requires a purification and upgrading process to remove impurities and $\mathrm{CO}_{2}$. This component is abundant in biogas (between $40 \%$ and $50 \%$ ) and it may lead to the formation of acid products, besides dramatic lowering gas 
heating value. Several techniques have been proposed, but each application needs an evaluation, to define its requirements $[9,10]$. In general, methane purity higher than $95 \%$ may be obtained through physical or chemical treatments, with an energy consumption ranging between $0.3-0.8 \mathrm{kWh} / \mathrm{Stm}^{3}$ of raw biogas [9]. Also, cryogenic purification has gained attention in the last decades [10]. This choice may prove to be relevant, due to the possibility of coupling purification and liquefaction, and its high performance in terms of purity; Baccioli et al. in [10] reported an energy consumption (purification and liquefaction) of $0.61 \mathrm{kWh} / \mathrm{Stm}^{3}$. In the case of traditional upgrading systems, such as membrane, absorption, or adsorption, a further step to reduce the $\mathrm{CO}_{2}$ concentration under $50 \mathrm{ppm}$ is required before the liquefaction plant.

Methane liquefaction requires heat removal in a wide range of temperatures and commercial processes are mainly focused on large-scale applications (thousands of tonnes of LNG per day) for fossil LNG [11]. Bio-LNG requires small/micro liquefaction plants (5-50 tonnes per day) and the suitable processes may differ radically from a large-scale application due to economic and practical reasons.

In small-scale applications, more attention must be dedicated to capital expenditures [12] whilst specific energy consumption may be regarded as the main driver of selection in the largest plants.

Generally, biomethane is liquefied through an external cycle, operating with a suitable working fluid: reverse Joule-Brayton cycle operating with nitrogen [13], mixed refrigerant cycles [14,15], Stirling reverse cycles [16], or Linde-Hampson cycles and their improvement (called "Internal Refrigerant cycles" in this study).

Reverse Joule-Brayton cycles are equipped with one or more turbo-expander to achieve the low temperature required by the process and recover part of the compression work. This type of system has been largely studied in the literature: Lee et al. in [17] reported the performance of a $2 \mathrm{~kW}$ test rig operating with neon to achieve the temperature of $77 \mathrm{~K}$. The turbine achieved an isentropic efficiency of $86 \%$ and found out that a good regenerator design is a cornerstone for achieving low temperatures. Lunkova et al. in [18] proposed a propane pre-cooling cycle before the cold box of Joule-Brayton reverse cycle to reduce the energy consumption by about $23 \%$ for a small-scale liquefaction plant. Khan et al. in [19] simulated a single nitrogen expansion process and a dual expander process, claiming a specific consumption respectively of 0.745 and $0.501 \mathrm{kWh} / \mathrm{kg}$ LNG. Qyyum et al. [20] claimed excellent performances by inserting a vortex tube system in the refrigerator cycle (nitrogen) instead of a cryogenic turbine, with specific consumption of $0.59 \mathrm{kWh} / \mathrm{kg} \mathrm{LNG}$.

Due to its relative compactness and simplicity, the reverse Joule-Brayton cycle can be adopted even in the cryogenic refrigeration of supercapacitors, as reported in [21], or for onboard boil-off gas reliquefaction in LNG carriers [22,23].

Mixed refrigerant cycles are commonly adopted in large-scale liquefaction plants [24], due to their large time response in the case of mass flow fluctuations with multiple potential start-ups during the year $[25,26]$ and to the need for a pre-cooling section to achieve high efficiency, which is not compatible with small-scale systems. However, in the literature, some authors propose single refrigerant loop mixed refrigerant cycles to liquefy biomethane [27] and few manufacturers have been proposing this type of cycle (without precooling section) for larger digestion plants [28]. Obviously, mixed refrigerant cycles are more efficient than the Joule-Brayton cycle, due to the better match of the heat transfer curves [29].

Stirling technology is suitable for small plants ( $2-3 t$ /day) due to the high specific consumption [16] but it is interesting for its relatively low investment cost and simplicity.

"Internal refrigerant" cycles achieve the cooling effect without using any other fluid than the biomethane or natural gas itself. Among the first proposed solutions, LindeHampson process provides a simple scheme and reduced number of elements. Initially designed as an air liquefaction system, it implies incoming gas flow is compressed and cooled to room temperature. A Joule-Thompson valve expands the gas to room pressure to accomplish liquefaction; the liquefied flow is extracted in the phase separator from the liquid-steam mixture, while vapor is constantly recirculating into the heat-exchanger; 
replenishment system restores the flow rate [30]. A cryogenic expander can be included in the scheme, deploying the liquefaction over several heat exchangers to obtain better results in terms of energy efficiency. This layout was named after Claude cycle [30]. Kapitza cycle, which will be further investigated, could be seen as a Claude cycle variant. Kapitza cycle is claimed to be very effective [31] in comparison with other solutions when it deals with air liquefaction, hence the interest in assessing its performance in natural gas or biomethane liquefaction.

Few studies extensively focused on internal refrigerant cycles, despite several companies are proposing this technology on the market in recent years. Capra et al. [32] offer a comparative analysis adopting five different liquefaction technologies, for a production flow of $4.6 \mathrm{t} / \mathrm{d}$ of LNG. Their evaluation relies on the distinction between "open cycles" and "closed cycles", i.e., between cycles without and with external cooling fluid. They include a Claude cycle, indicating a specific consumption of $4184 \mathrm{~kJ} / \mathrm{kg}$ of LNG. In [33] a comparison between two different internal refrigerant techniques for liquefying a small amount of LNG $(1 \mathrm{~kg} / \mathrm{s})$ is performed. The authors found out $20 \%$ reduction in power consumption if the Joule-Thompson valve is replaced by a cryogenic turbine.

Kapitza cycle is one of the most interesting internal refrigerant cycle solutions. This technology is proven to be even more compact than Joule-Brayton reverse cycle taken into evaluation when dealing with the boil-off gas on LNG ships. For instance, [34] concluded that Kapitza Cycle is preferable to a Reverse Brayton Cycle due to its reduced volume. Exploiting the waste heat that has been generated by the auxiliaries could represent an interesting way to improve the performance of the cycle. In [34] absorption chiller technologies are implemented both in an internal refrigerant and in an external refrigerant liquefaction cycle for Natural gas. Their use reduces specific energy consumption by 26-35\%.

Regarding the liquefaction cost, the internal refrigerants cycles achieve a liquefaction cost between 20.0 and $24.0 \mathrm{c} € / \mathrm{kg}$ for a Linde cycle operating for $8250 \mathrm{~h}$ [35]. The cost obviously depends on several assumptions, such as the boundary conditions (particularly biomethane pressure and liquid pressure) cycle layout, and the liquefaction technology adopted.

Various architectures are possible with an internal refrigerant cycle, mainly depending on the number of recirculation streams in the cold-box and the number of expanders. Since capital expenditures represent a constraint in small-scale plants, it is obvious that plants should be designed according to a trade-off between system efficiency and simple layout. The use of absorption chillers recovering heat from compressors as proposed in [36] is a viable idea to keep a simple layout and increase the system performance. This study aims at thermodynamically and economically comparing two different pathways in smallscale liquefaction cycle with internal refrigerant: the use of complex layout with good thermodynamic performance or the use of simple layout boosted by absorption chillers.

\section{Materials and Methods}

This chapter is divided into two sections, to better discuss the main materials and data that are under analysis (Section 2.1) and the Methods that are at the basis of the analysis itself (Section 2.2). The latter point, in particular, has been split into further parts, to stress the several aspects of the analysis.

\subsection{Case Study}

This section introduces the main elements of the models that have been selected to perform the simulation and the optimization. At first, the Base case (Section 2.1.1) and, then, successive implementations (Section 2.1.2) are explained, devoting adequate space to define the proper characteristics of each solution. 


\subsubsection{Base Case}

The starting point (Base Case, BC) relies on Kapitza Cycle, as illustrated in Figure 1. After a 3 stage compression, intercooled by three air coolers, the biomethane flow 7 is cooled down in the Cold Box (CB), before being split into two flows. 9 is sent back to the CB exchanger to be furtherly cooled while 16 is expanded in a cryogenic expander. Hence flow 17 is low pressure and low temperature, and it is mixed with cool and gaseous biomethane coming from the separator. The main cold-box is composed of a single multi-flow heat exchanger, a usual device in refrigeration systems. 14 would provide the cooling effect, without using any external fluid for this purpose. Fresh biomethane, coming from the upgrading system, is fed by the compressor stage C-2, because its pressure is 15 bar and it doesn't need the first stage of compression.

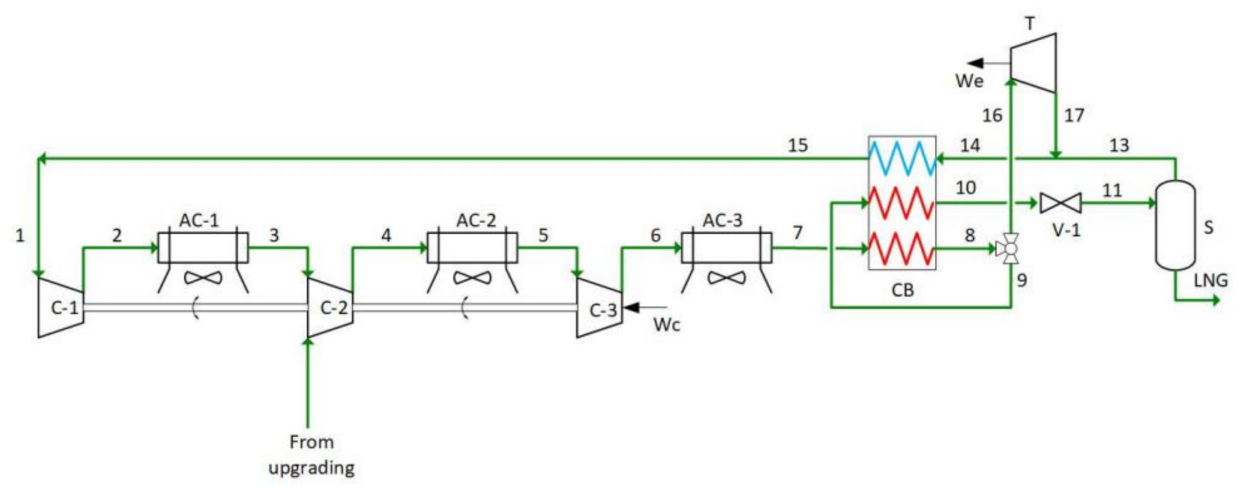

Figure 1. Base case (BC).

\subsubsection{Scheme Modifications}

In the following, modifications to $\mathrm{BC}$ scheme are proposed, with the aim to improve the specific consumption. Firstly, the options of modifying the cycle with the integration of expander or Joule-Thompson valves and then with the recovery of compression waste heat are introduced.

The first setup is a Kapitza process with double expander (DE) cycle, in which a second expander was added to the Kapitza cycle to process the flow coming from the compressor post-refrigerator, inspired by the Heylandt solution. The main function of expanders is to produce the cooling effect necessary for gas liquefaction. The possibility of obtaining two flows at different temperature levels may allow a better match between the heat transfer curves in the cold-box. In addition, the use of a second expander may increase the recovery of mechanical work produced by the expansion of the fluid, with obvious benefits with respect to the total energy required by the system. The compression is run through three compressor stages in series, with external inter-refrigeration. The cycle is depicted in Figure 2. After compression and air-cooling, the gas flow 7 is split into two. Flow 8 is sent to Cold Box (CB) where it is cooled down (9) and furtherly split in two: 21 is expanded in T-2 and is then mixed with the gaseous part coming from the separator S. Flow 10 is cooled again in CB (11) and it is subsequently expanded in a Joule-Thompson valve $\mathrm{V}-1$. The two-phase product is then separated at point 18, while the other flow that has been produced by the division of 7 , is sent to T-1 to generate an additional cooling effect in the Cold Box. The main criticality of this solution is the second expander: in fact, small-scale cryogenic turbines do not have a developed market and their cost might be extremely high. The presence of a double expander in the cycle potentially increases the cost. In addition, small-scale microturbines are characterized by a high rotational velocity (up to $100 \mathrm{k} \mathrm{rpm}$ or even more), thus increasing the risk of failures and reducing the reliability of the system. 


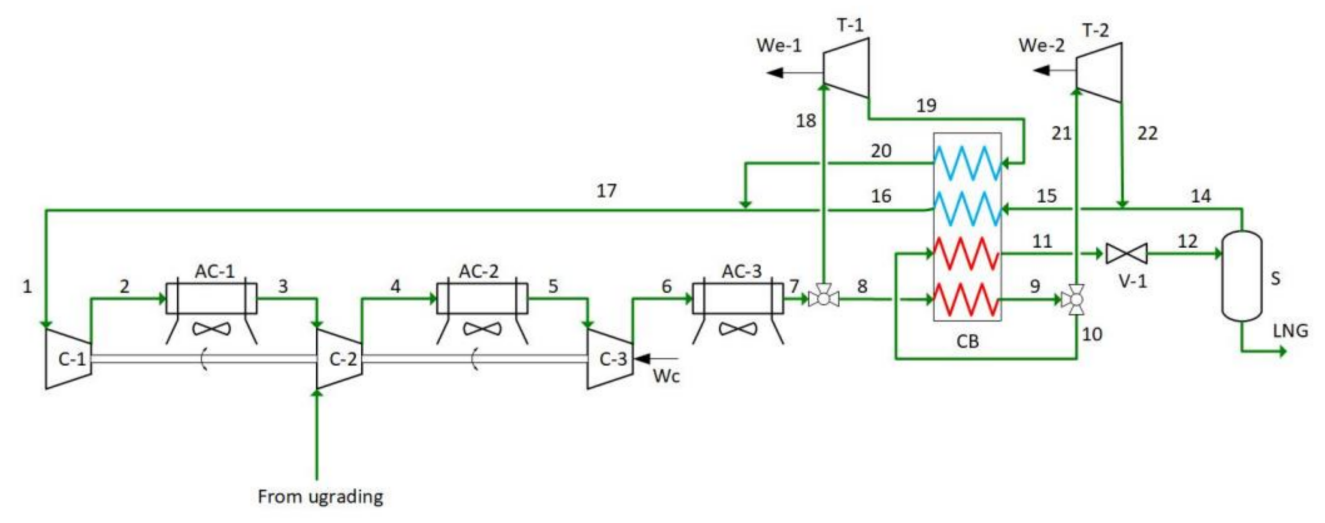

Figure 2. Kapitza process with double expander (DE).

If these features were not sufficiently favorable to justify another expander, similar advantages on the heat exchange side by using the introduction into the base system of a simple expansion valve as a secondary element of refrigerant effect generation. The best placement of the valve has been determined by simulating several options and the configuration represented in Figure 3 was selected. Flow 20 is laminated into the V-1 valve inside the two-phase region, generating the two-phase flow 21 that is introduced into ColdBox. The refrigerant effect provided by this evaporation flow should be significant, considering the latent heat of evaporation. Hereafter, it will be referring to this setup as Kapitza process with secondary valve (SV).

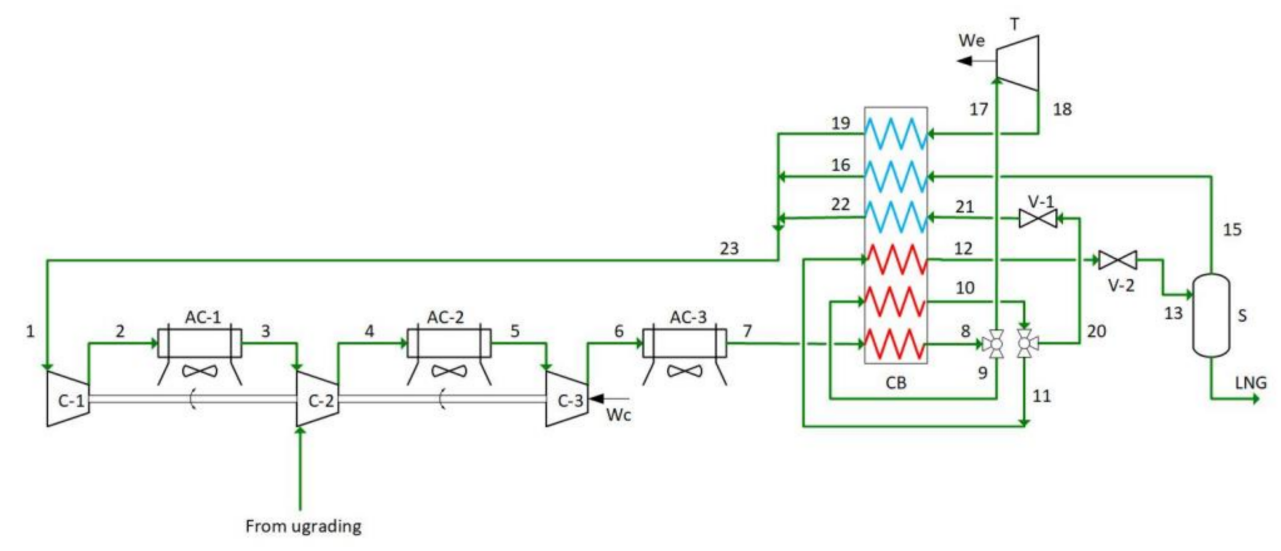

Figure 3. Kapitza process with secondary valve (SV).

It is possible to appreciate that, if J-T is simpler than a cryoturbine, a more complex layout is required by the heat exchanger.

The systems considered up to this point inevitably wasted a certain amount of heat in the multi-stage compressor. Since this waste heat is available at a fairly high temperature (over $150^{\circ} \mathrm{C}$ ), part of it may be recovered to feed an absorption refrigeration machine. The coolant effect of the chiller may be subsequently aimed at precooling the gas before entering the coldbox or precooling the gas entering the compressors. Absorption chillers differ from compression machines in the type of energy they require as a feeding. If the latter require mechanical energy, a form of valuable energy produced in most cases by electric motors, absorption machines are designed to operate mainly powered by thermal energy. This kind of device may be advantageous if recovery heat is available, which would otherwise be dispersed in the environment. Chilling performance depends on the technology and the fluids coupling used in the process. However, they require a moderate temperature recovered heat.

The conceptual schemes of solutions based on Kapitza cycle and absorption chillers integration are reported in Figures 4-6. Chillers were added to the basic cycle, in order not 
to furtherly complicate the system and to identify more clearly the contribution provided by the introduction of these devices.

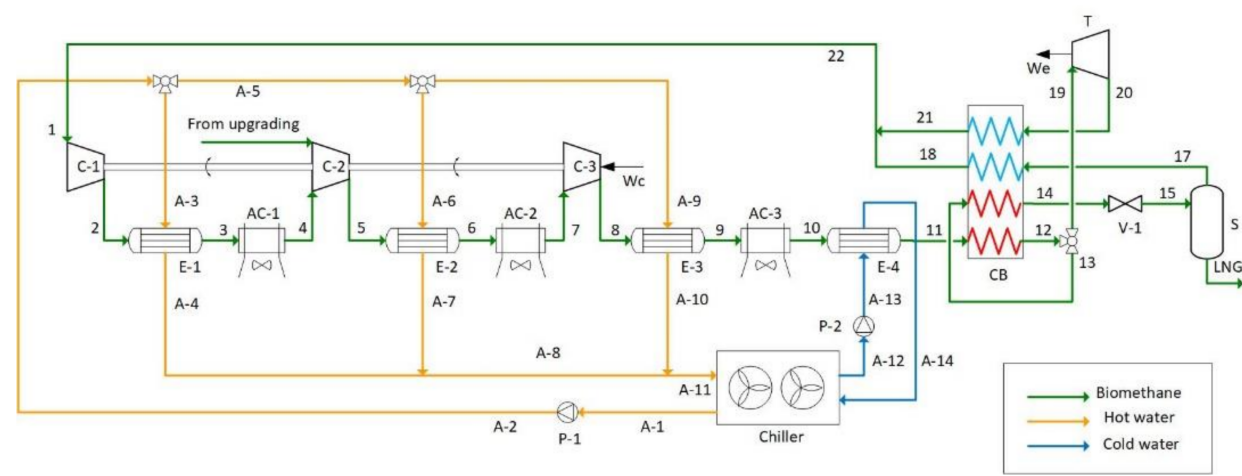

Figure 4. Absorption chiller set-up 1 (AC-1).

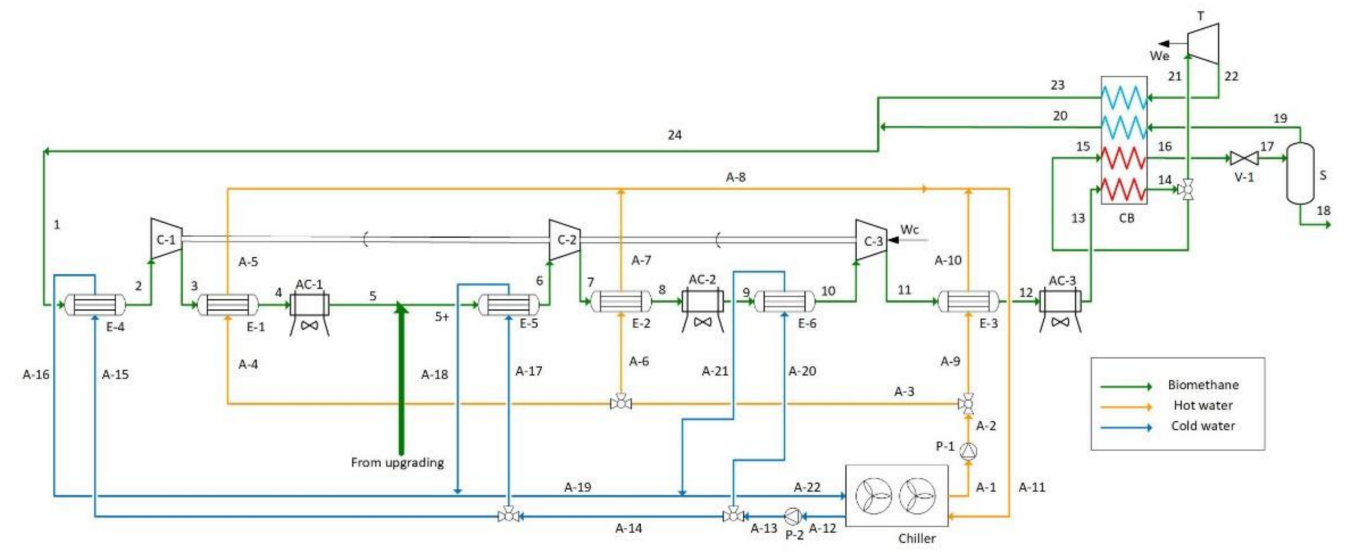

Figure 5. Absorption chiller set-up 2 (AC-2).

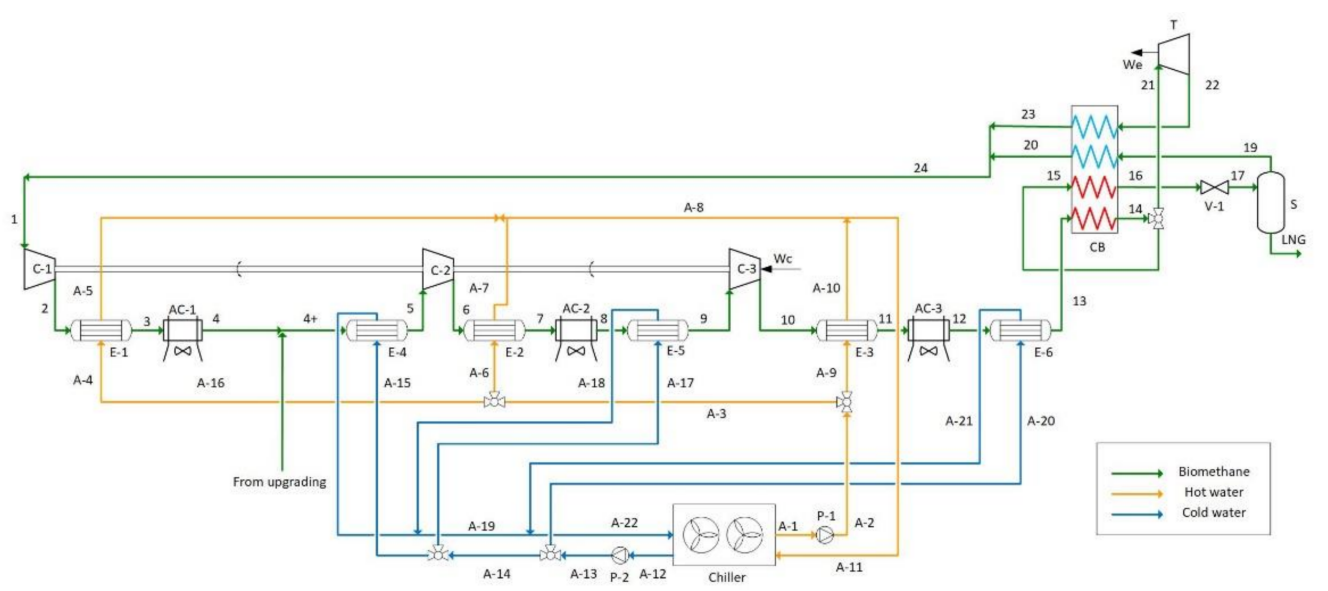

Figure 6. Absorption chiller set-up 3 (AC-3).

A water circuit enables the heat recovery from the compressors: according to Figure 4, the biomethane flows 2,5 , and 8 are sent to a heat exchanger, before being furtherly cooled down by air coolers; this heat exchanger exploits the temperature of compressed gas (over $100{ }^{\circ} \mathrm{C}$ ) to heat the water flow up to $90^{\circ} \mathrm{C}$. The water flow is, hence, employed in the generator of an absorption chiller to cool biomethane down, thus reducing the energy requested by liquefaction.

Among the different ways that cold water flow could be used, here the analysis focused on the removing of the heat in two points, before the compressor, to reduce the 
work of compression, and before $\mathrm{CB}$, to reduce the duty requested by the heat exchanger. The analysis has been conducted by increasing complexity. In the first one (AC-1), chillers are useful to decrease the temperature of flux 11, when approaching the Cold box. In AC-2, they are employed in reducing the temperature before the different compressor stages. AC-3 combined the previous solution, with the chilling flow at both the inlet of the CB and the inlet of the compressors. In AC-2 and AC-3 setups, air coolers, and shell and tube heat exchangers are implemented, to furtherly decrease the temperature, by exploiting the cool water produced by the absorption chiller. These steps could be useful to identify the individual effect in reducing the specific power consumption.

\subsection{Methodology}

The commercial software Aspen HySys has been employed to perform simulations of previously illustrated processes. Peng-Robinson equation of state was considered to evaluate thermodynamic states and fluid properties in the cycle [37].

This study involves the analysis of small-scale systems, with a daily production of liquefied gas ranging between 1 and 10 tons per day; specifically, the upper end of this range is considered, and it corresponds to an LNG flow rate of about $417 \mathrm{~kg} / \mathrm{h}$. This value will hence coincide with the make-up flow, to be provided in the process to restore the total flow rate. High methane purity is required for biomethane liquefaction, due to the risk of $\mathrm{CO}_{2}$ freeze-out [11]. Further steps of purification, to reach an adequate grade of purification, are here neglected because they are considered a common starting point for all the different cycles. For this reason, in the simulation, this flux is represented as a pure methane flow.

In Table 1 the process parameters used to perform the simulations are enlisted.

Table 1. Process parameters.

\begin{tabular}{cc}
\hline Parameter & Value \\
\hline Input temperature & $30{ }^{\circ} \mathrm{C}$ \\
Inlet gas pressure & $15 \mathrm{bar}[38]$ \\
Pressure to the LNG tank & $4 \mathrm{bar}$ \\
Pressure losses in heat exchangers and phase separators & $10 \mathrm{kPa}[1]$ \\
Inter-refrigeration outlet temperature & $45^{\circ} \mathrm{C} \mathrm{[1]}$ \\
Minimum pinch point in exchangers & $5{ }^{\circ} \mathrm{C} \mathrm{[1]}$ \\
Efficiency of compressors and expanders & $75 \%[1]$ \\
\hline
\end{tabular}

\subsubsection{Thermodynamics Optimization}

In Aspen Hysys several optimization algorithms are available. In this paper, the BOX algorithm has been chosen: this is a sequential search algorithm, able to deal with the non-linear problem [39].

The target function to be optimized is the specific energy consumption per unit of LNG produced, which may be expressed as:

$$
C_{s}=\frac{W_{n e t}}{\dot{m}_{L N G}}\left[\frac{k W h}{k g}\right]
$$

where $\dot{m}_{L N G}$ is the biomethane flow and the net mechanical work $W_{\text {net }}$ is defined as:

$$
W_{\text {net }}=\sum_{i=1}^{N}\left(W_{\text {compr }}+W_{\text {fan }}\right)-\sum_{i=1}^{M} W_{\text {exp }}
$$

$N$ and $M$ are the numbers of compressors and expanders operated in the process, $W_{\text {compr }}, W_{\text {fan }}$ and $W_{\text {esp }}$ mechanical work of compression, ventilation, and expansion of individual machines. Power absorbed by the ventilation system is calculated approximately as $1.7 \%$ of the thermal load removed by air-coolers [40]. 


\subsubsection{Exergy Analysis}

The exergy of a system is the work that can be obtained from the system in the transition from an initial state to a state of equilibrium with the environment through a hypothetical reversible process. Under steady-state conditions, and by neglecting the contribution due to kinetic and potential energy, the physical exergy of a flow takes the form:

$$
E x=\dot{m} \cdot\left[\left(H-T_{0} S\right)_{T, p}-\left(H-T_{0} S\right)_{T_{0}, p_{0}}\right]
$$

where $H, S, T$ and $p$ are, respectively, enthalpy, entropy, temperature, and pressure of the system under analysis, while $T_{0}$ and $p_{0}$ are temperature and pressure in the death state.

The exergy destruction of the generic $j$-th component with $i$ mass inlets/outlets is expressed as:

$$
\Delta E x_{j}=-\sum_{i} \dot{m}_{i} T_{0} \Delta S_{i}
$$

The overall exergy destruction is evaluated as:

$$
\Delta E x_{T}=\sum_{j} \Delta E x_{j}
$$

The second law efficiency expression is therefore calculated as:

$$
\eta^{I I}=1-\frac{\Delta E x_{T}}{W_{n e t}}
$$

\subsubsection{Implementation of Absorption Chillers}

Technical specifications for absorption chillers are taken from [41], a commercial cata$\log$ for absorption chillers operating with hot water as a heat source. At nominal conditions the chillers require a water flow at the temperature of $90^{\circ} \mathrm{C}$, exploiting the available waste heat (hence, this must be just over $100^{\circ} \mathrm{C}$ ). Refrigeration machine performance is concisely expressed by Coefficient of Performance, defined as:

$$
\mathrm{COP}=\frac{Q_{c}}{Q_{\text {in }}}
$$

where $Q_{i n}$ is the heat recovered from the compressors and supplied to the chiller generation system, and $Q_{c}$ is the useful effect of the chiller, cooling effect. The typical COP of these machines is 0.7 . The useful effect is enacted by producing a cold water flow, at a temperature of $7^{\circ} \mathrm{C}$.

\subsubsection{Economic Evaluation}

The indicator chosen for economic evaluation was the Levelised Cost of Liquefaction (LCOL). LCOL is the total cost of liquefaction of biomethane through a given system. In other words, it represents the part of the selling price to be attributed to LNG produced by the liquefaction plant in question, to reach the break-even point at the end of the plant's life [42].

First, the Purchased Equipment Cost (PEC) of each component was calculated; subsequently, these values were increased by appropriate factors to take into account operational pressure, materials, and associated direct and indirect costs [43].

PEC is evaluated by the formula:

$$
\log _{10} C_{p}^{0}=K_{1}+K_{2} \log _{10}(A)+K_{3}\left[\log _{10}(A)\right]^{2}
$$

where:

$C_{p}^{0}[€]$ is the purchased cost of the equipment;

$A$ is the size parameter for the equipment (e.g., compression power for compressors); 
$K_{1}, K_{2}, K_{3}$ are empirically obtained constants, that are related to the specific piece of equipment under analysis.

The latter relationship is valid at ambient pressure and for carbon steel products. To take into account the real operating pressure in acquiring instruments able to endure such conditions, it is introduced a pressure factor $F_{p}$; with the same criteria, a bare module factor $F_{B M}$ is introduced to consider the construction material that has been assumed for the equipment.

Empirical correlations for $F_{p}$ and $F_{B M}$ are reported in [43].

$L C O L$ is, then, defined by the formula:

$$
L C O L=\frac{I_{0}+\sum_{t=1}^{n} \frac{M_{t}+L_{t}+F_{t}}{(1+t)^{t}}}{\sum_{t=1}^{n} \frac{P_{t}}{(1+i)^{t}}}
$$

where:

$I_{0}[€]$ is the initial purchasing cost of the plant (that was estimated with the previous formulas);

$M_{t}[€]$ is the annual maintenance expenditures;

$P_{t}[\mathrm{~kg}]$ is the annual LNG production;

$i$ is the discount rate;

$n$ [years] is the expected lifetime of the plant.

The annual maintenance expenditure has been estimated to be $4 \%$ of the initial cost of the investment. The annual production of LNG was calculated by assuming a daily liquefaction rate of $10 \mathrm{t} /$ day on 350 out of 365 days of annual plant activity. A 5\% discount rate and an expected life of 20 years were assumed.

The cost of biomethane production depends on biomass source and anaerobic digestion + upgrading plant. For this reason, this cost is neglected in order to analyze only liquefaction additional cost. The price of electricity is the most important parameter that deeply affects the assessment. Hence, a sensitivity analysis on the price will be subsequently introduced.

\section{Results and Discussion}

In the following paragraphs, only the main results obtained performing the optimization of the models in the analysis are illustrated and discussed, whereas details about the same models (mass flows and energy flows) are reported in Appendix A. At first, the energy (Section 3.1) and the exergy (Section 3.2) results are issued, to leave the last paragraph (Section 3.3) to the economics aspect.

\subsection{Thermodynamic Analysis Results}

The results of energy consumption for the various cases are represented in Figures 7 and 8 . Comparing the Base Case with DE and SV, i.e., the set-ups obtained adding elements of expansion to the Base Case, the optimization ended with similar results. Indeed, the entire cycles share the same optimized parameters. Even the maximum pressure is $70 \mathrm{bar}$ for all three cycles. Adding a second expander in DE does not generate additional work: in fact, the work generated by the two expanders is just the same generated in the case of SV single expander. Hence, increasing the complexity of the system with expansion devices does not show any improvement and it does not seem justified. 


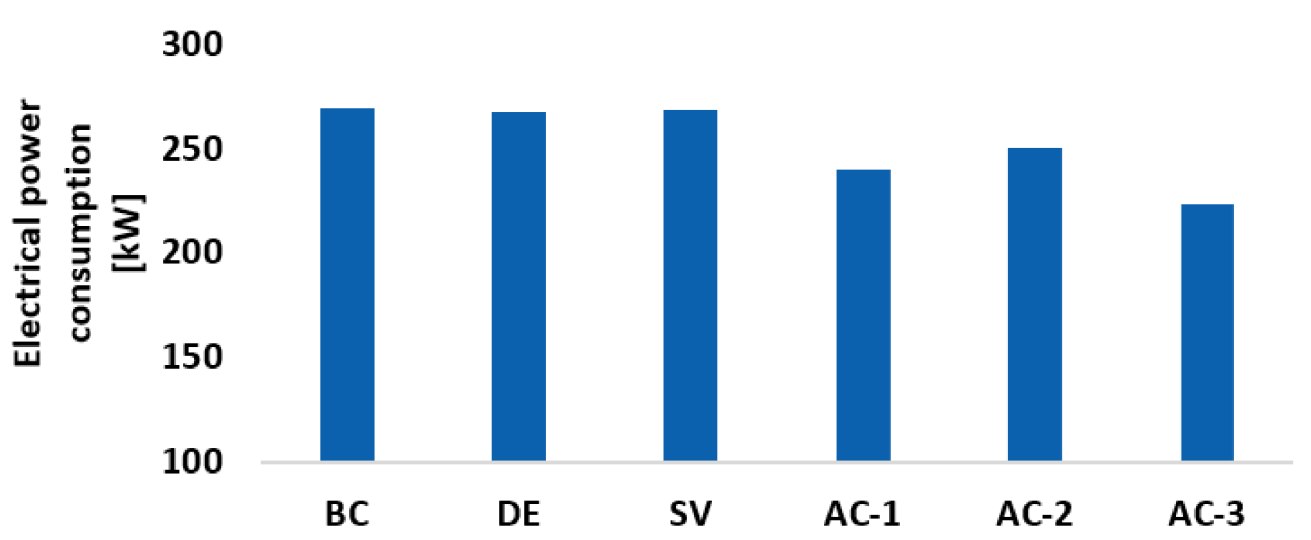

Figure 7. Electrical power consumption results for the several cases.

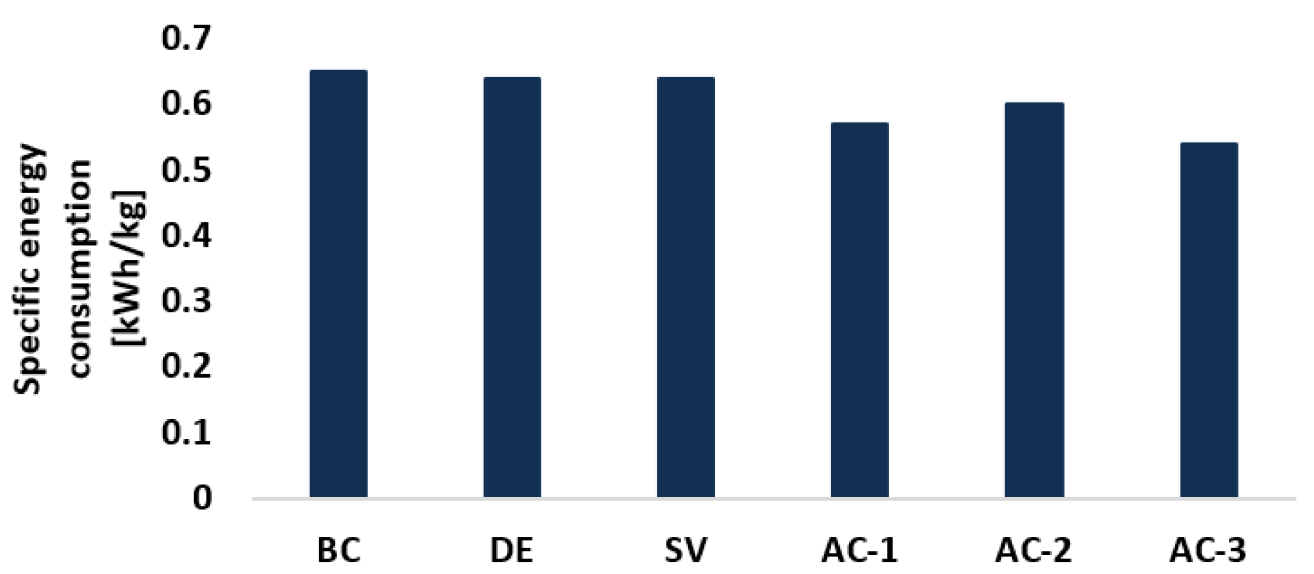

Figure 8. Specific consumption results for the several cases.

The three processes with absorption chillers and thermal recovery from the compressor show improvements in specific consumption more significantly than the first two solutions.

The reason for the reduction in specific consumption could be explained by noticing, in $\mathrm{AC}-1$, the minor duty required by the heat exchanger: the chiller located before the cold-box allows a reduction of heat duty higher than $22 \%$ with respect to the Base Case. If this reduces the dimension of the cold box, with benefits in economics, as written in the following, it also reduces compression power (Figure 9) because of the minor need for recycling fluid (Figure 10). This implies that the compressors (that have to deal with a flux that comprehends both the recycling and the backup flows) should elaborate a smaller flow, with savings in energy consumption.

In AC-2, the reduction in specific consumption is attained by cooling the flows before the compression stages, this is due to the power consumption of the compression: the work done is proportional to the temperature of the fluid at the inlet of the compressor. This reduction could be seen as well in Figure 9. The temperature before the cold-box is achieved through the air-cooler, as in the Base Case: hence, the heat duty required by the cold box is similar to that in the Base Case. The flow rate is greater than in AC-1, and this is because of the difference in compressor stage inlet temperature if compared to the previous cases: when the temperatures before the compressor were managed by the intercooler, they produce a biomethane flow at $45{ }^{\circ} \mathrm{C}$; the absorption chillers decrease furtherly this temperature down to less than $15^{\circ} \mathrm{C}$. Hence, the new optimal point admits higher flow, and minimizing it is not a priority as it was in the other cases. 


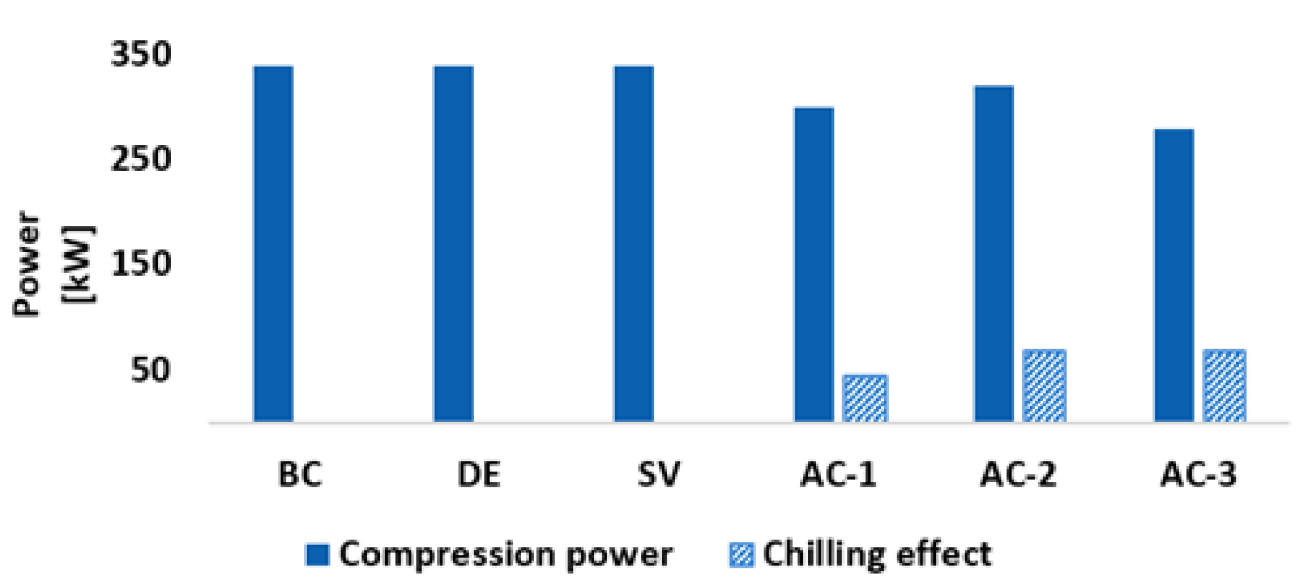

Figure 9. Compression power and recovered chilling effect for the various cases.

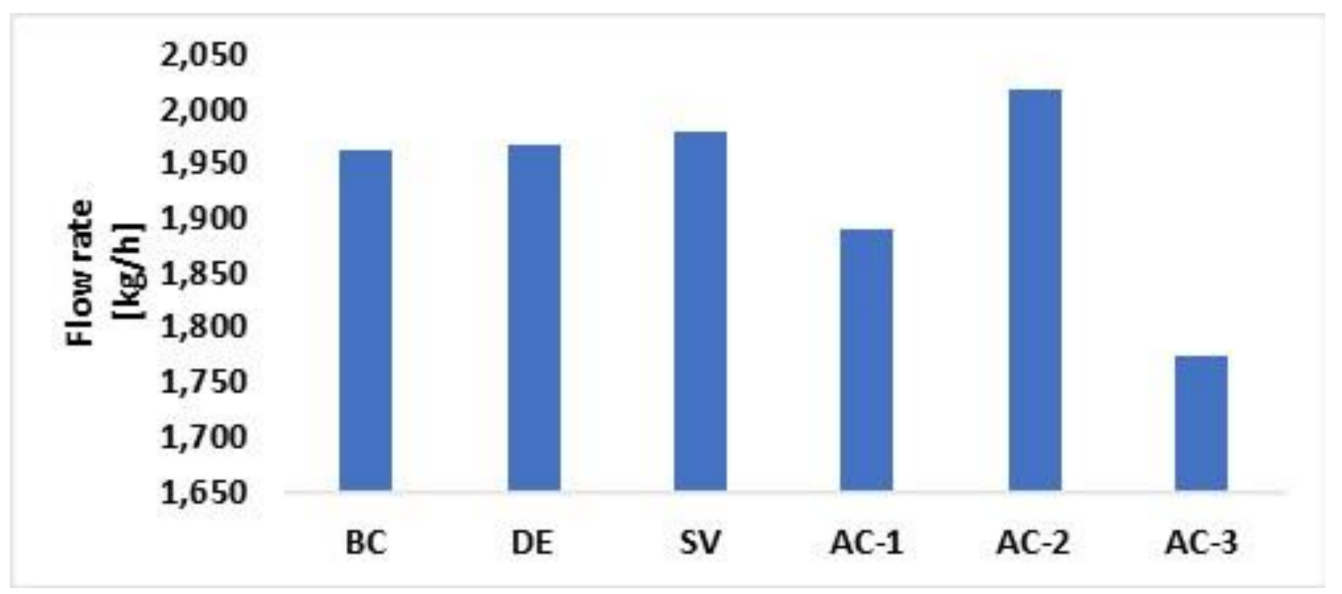

Figure 10. Maximum flow rate in the various cases.

The results show that the reduction in compression work due to chilling the inlet flow is significantly lower than the savings obtained by precooling the flow before the Cold Box (Figure 8). AC-2 adds a negligible save, with respect to the Base Case, but with a higher complexity: it should be noted that the pre-compressor cooling process (AC-2) has higher specific consumption with respect to (AC-1), although AC-2 implies a larger deployment of devices. AC-3 represents the combination of the two previous solutions and, as it could be expected, it has the lowest specific consumption. It should be emphasized that even this solution introduces the largest amount of additional complexity, requiring more pumping and piping for circulation of water used as a heat medium with respect to the Base Case. In the next figures (Figures 11-16) the cold box composite curves are represented for the various cases:

The hot composite line represents the part of the methane flow that comes from the compressors and is liquefied at supercritical pressure, before being sent to the J-T valve. It almost presents the same trend in every figure, with the higher temperature part is linearly decreasing with heat flow: The part at lower temperature refers to the flow that is furtherly cooled down till liquefaction and it is eventually sent to the J-T valve (flow 9 in Figure 1). It is worth noticing that in the cases in which the absorption chillers precools the methane at the cold-box inlet (AC1 and AC3), the straight part of the hot composite curve is "shorter" than the other cases and the heat transfer curves are closer. The cold composite represents the flow that is recirculated into the Cold Box to serve as "internal refrigerant". Interestingly the plateau at the low temperature part of the cold-box indicates a phase transition zone in VS (Figure 13). This represents flow21 (Figure 3) after the secondary throttling valve. 
The minimum pinch point is, higher than $5{ }^{\circ} \mathrm{C}$, according to the constraint imposed during the optimization, and the maximum temperature difference between the two flows is about $30^{\circ} \mathrm{C}$, which is acceptable for a plate and fin heat exchanger.

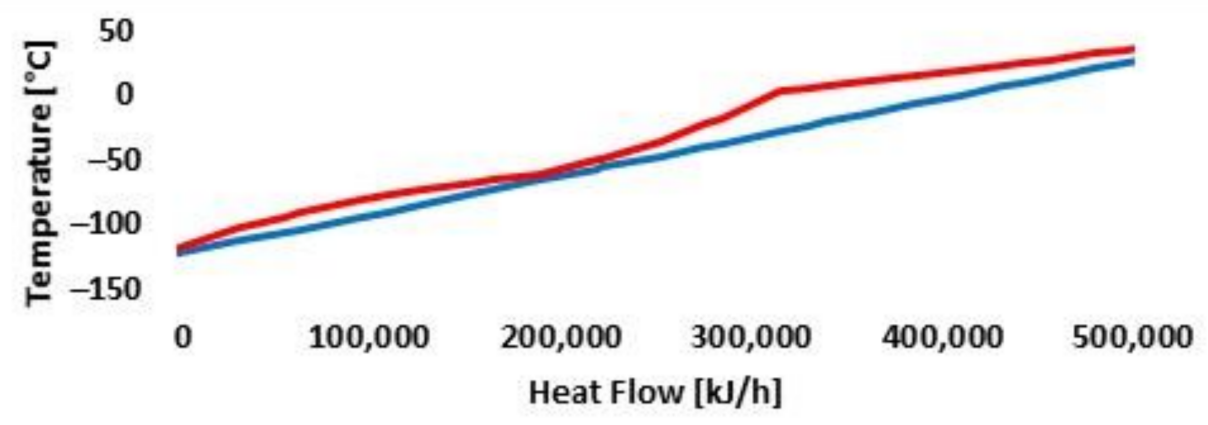

Cold composite —Hot composite

Figure 11. Heat transfer composite curves for Base Case Cold-Box.

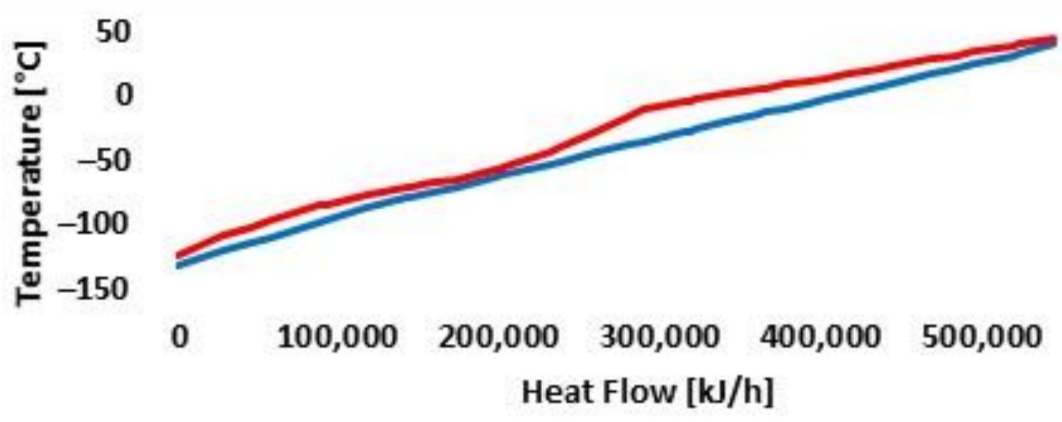

- Cold composite —Hot composite

Figure 12. Heat transfer composite curves for DE Cold-Box.

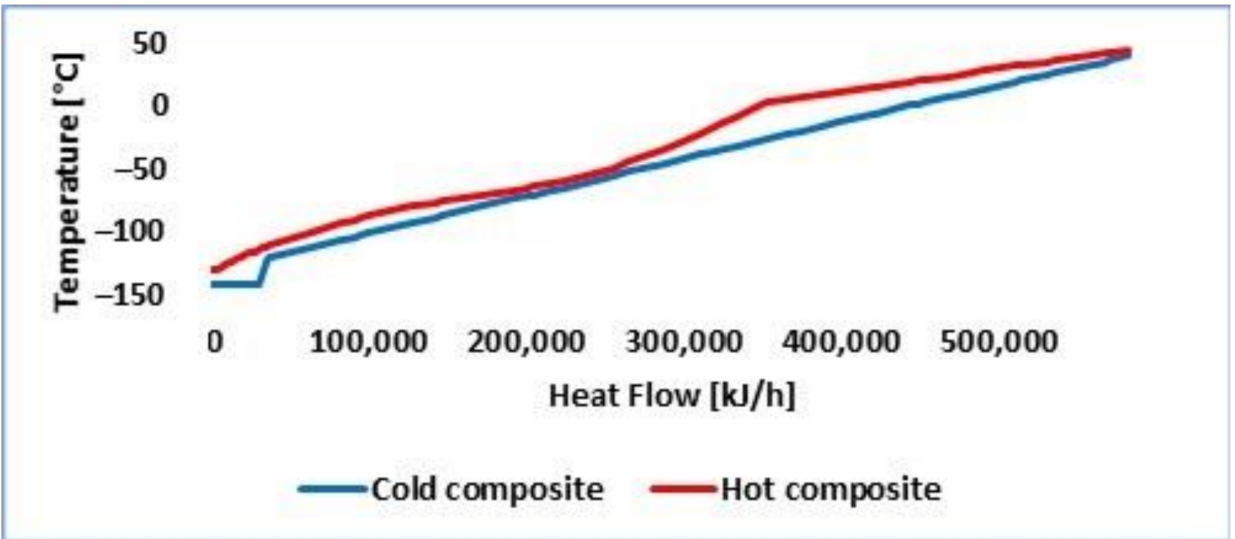

Figure 13. Heat transfer composite curves for VS Cold-Box. 


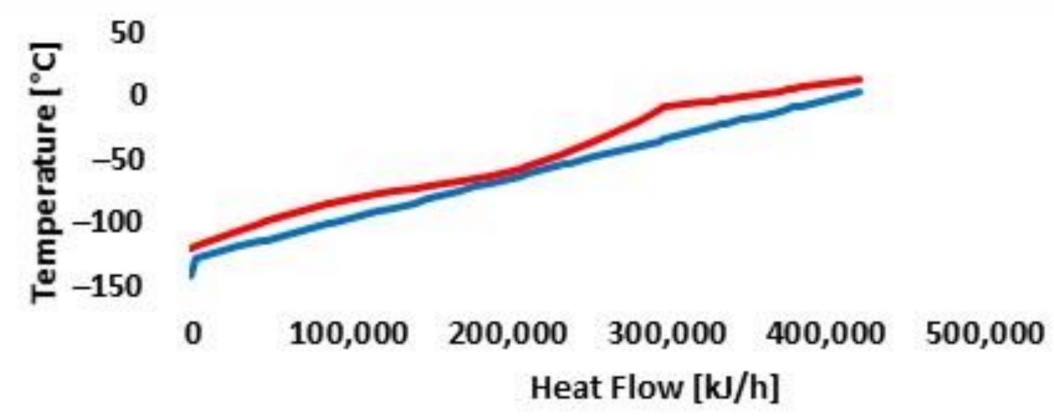

- Cold composite - Hot composite

Figure 14. Heat transfer composite curves for AC-1 Cold-Box.

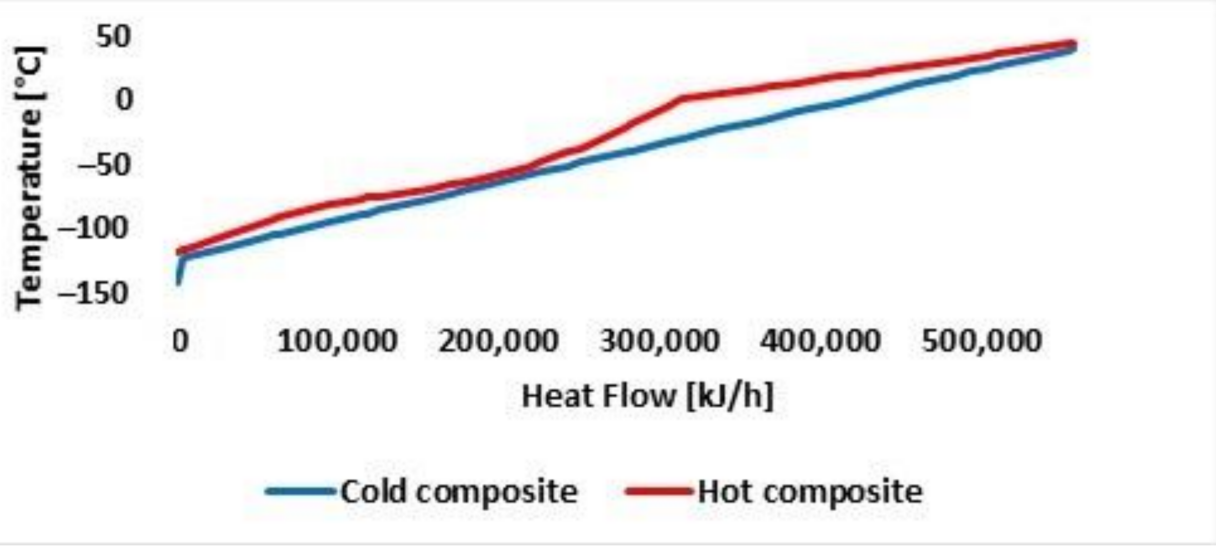

Figure 15. Heat transfer composite curves for AC-2 Cold-Box.

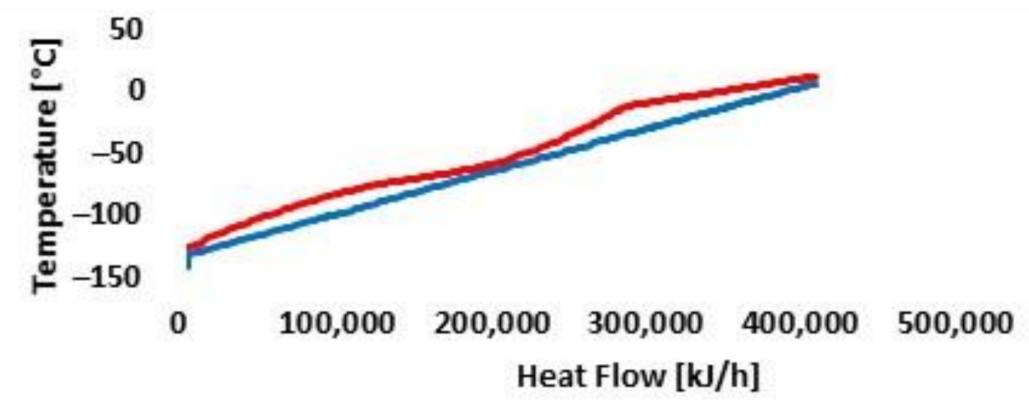

Cold composite - Hot composite

Figure 16. Heat transfer composite curves for AC-3 Cold-Box.

\subsection{Exergyc Analysis Results}

The results of the expressions enlisted at 3.3 are shown in Figure 17. From the analysis of the exergy destruction in the base Kapitza cycle, it is worth noticing that the highest contribution to exergy destruction is due to compressors and intercoolers. Further improvements of the layout do not lead to a relevant reduction of the exergy destruction. Only in the case of DE, the presence of a couple of expanders decreases exergy destruction in the cold-box, due to the better match between the heat transfer curves achieved with respect to the base Kapitza cycle. In addition, in this configuration, exergy destruction on the throttling valve is reduced, due to the lower mass flow rate circulating in the cycle. 


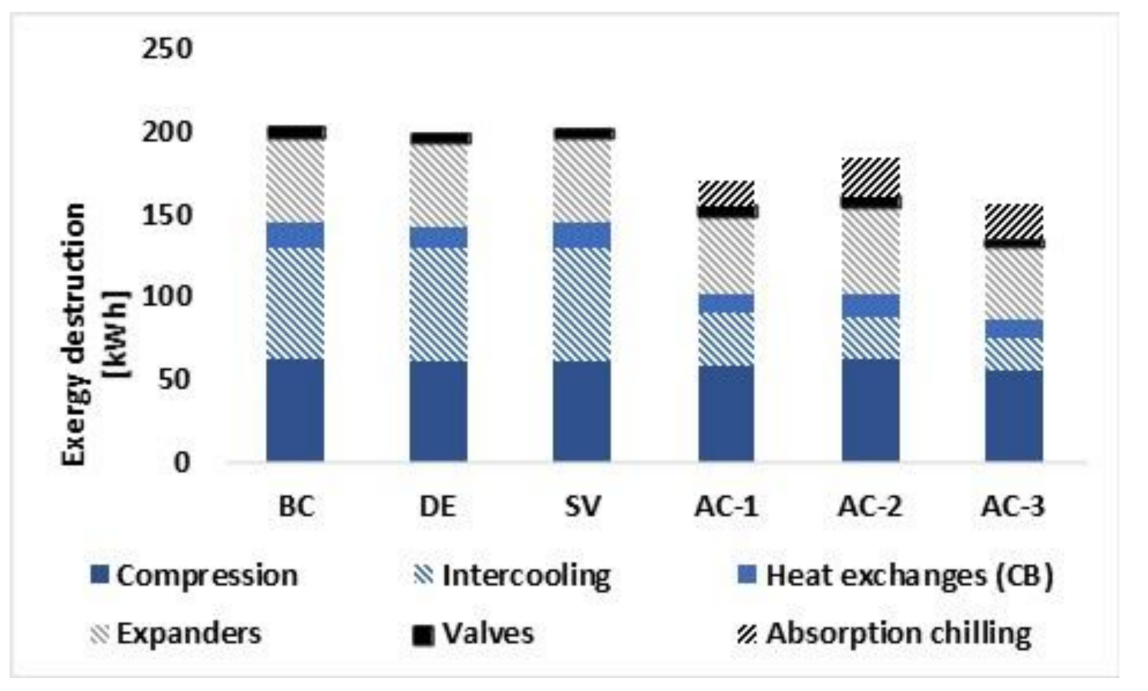

Figure 17. Exergy destruction for the various cases. Different colors refer to different elements of the system.

The introduction of a secondary valve does not bring any improvement to the base Kapitza cycle. The recovery of the heat of compression can reduce exergy destruction in the intercoolers. By introducing absorption chillers, according to the scheme AC-1, exergy destruction in intercoolers decreases almost three times. Specifically, exergy destruction in all three cases that adopt adsorption chillers is 16\% (AC-1), 10\% (AC-2), and 23\% (AC-2) less than those in $\mathrm{BC}$. In AC- 1 and $\mathrm{AC}-3$ the cooling at the biomethane compressor inlet reduces the exergy destruction in compressors. In AC-1 and AC-3, the cooling effect before the cold-box reduces the exergy destruction in the cold box: in fact, the lower temperature at which biomethane approaches the cold box allows the heat transfer curves to be better matched. A better thermal match is possible in the cold-box where, during liquefaction, methane tends to modify the slope of the heat transfer curve, due to the variation of the specific heat. The reduction of the temperature at the cold-box inlet tends to reduce the heat transferred at high temperatures, where the specific heat of methane is small.

The second law efficiency for the three configurations is reported in Table 2 and shows that the improvement to the base Kapitza cycle can achieve the $24 \%$ in the case of AC-3 configuration, while by adding an expander the improvement is actually small.

Table 2. Second law efficiency and improvement with respect to the base case for the several cases.

\begin{tabular}{ccccccc}
\hline & BC & DE & SV & AC-1 & AC-2 & AC-3 \\
\hline$\eta_{\text {ex }}$ & $24 \%$ & $25 \%$ & $24 \%$ & $28 \%$ & $26 \%$ & $30 \%$ \\
\hline $\begin{array}{c}\text { Improvement with } \\
\text { respect to BC }\end{array}$ & - & $+4 \%$ & 0 & $+16 \%$ & $+8 \%$ & $+25 \%$ \\
\hline
\end{tabular}

\subsection{Economic Results}

CAPEX related to the various devices of the analyzed systems have been estimated by the relationship in Section 2.2.4 and they are reported in Table 3.

In Figure 18 the overall capital expenditures of systems are represented, underlining the different costs of compressor, expansion system with generation devices, aftercooling system, coldbox, the separation column, and the absorption chilling system. The introduction of absorption chillers does not result, by itself, in significant changes for the cost of the plant: the cost of additional chillers and heat exchangers tend to compensate for the reduction in costs of other components: e.g., compressor and expander costs in AC-3 are $15 \%$ and $18 \%$ lower than the base case. Even if it has less effect on overall CAPEX, even the heat exchangers in the last three cases are smaller with respect to the Base Case and, 
consequently, their cost is $10 \%, 14 \%$, and $16 \%$ less, respectively for AC-1, AC-2, and AC-3. Hence, AC- 1 and AC- 3 show a CAPEX that is similar to the Base case, with a reduction in energy consumption. On the opposite, in AC-2, the cost of the compressor is comparable to that of the Base Case, becuse it elaborates a greater flow. Anyway, the adding of an adsorption chiller system increase the overall CAPEX of the set-up AC-2, respect to the Base Case.

Table 3. All values are expressed in $€$.

\begin{tabular}{|c|c|c|c|c|c|c|c|}
\hline & Compressor & $\begin{array}{c}\text { Expander + } \\
\text { Generator }\end{array}$ & Aftercooler & Coldbox & Separator & $\begin{array}{l}\text { Absorption } \\
\text { Chilling System }\end{array}$ & Tot \\
\hline Base & 675,000 & 360,000 & 100,000 & 80,000 & 20,000 & - & $1,235,000$ \\
\hline $\mathrm{DE}$ & 672,000 & 444,000 & 100,000 & 73,000 & 20,000 & - & $1,309,000$ \\
\hline SV & 675,000 & 360,000 & 100,000 & 77,000 & 20,000 & - & $1,232,000$ \\
\hline AC-1 & 610,000 & 316,000 & 90,000 & 70,000 & 20,000 & 116,000 & $1,222,000$ \\
\hline AC-2 & 642,000 & 356,000 & 86,000 & 68,000 & 20,000 & 183,000 & $1,355,000$ \\
\hline$A C-3$ & 573,000 & 292,000 & 80,000 & 67,000 & 20,000 & 205,000 & $1,257,000$ \\
\hline
\end{tabular}

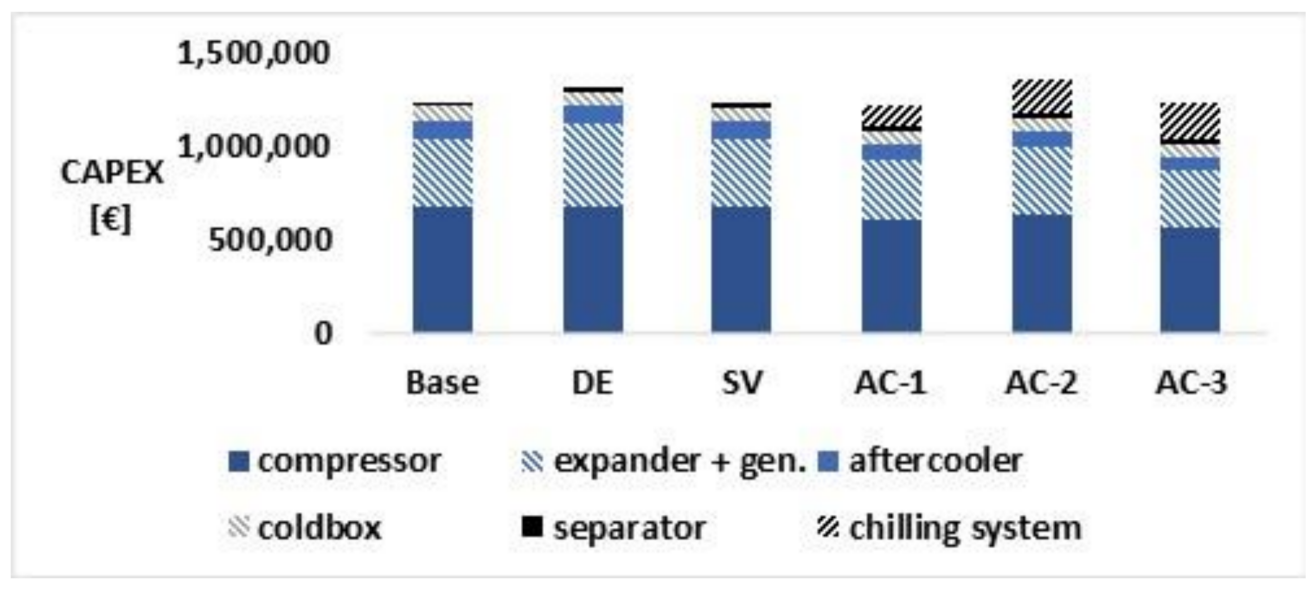

Figure 18. CAPEX of the various cases. Different colors refer to different elements of the system.

Once the PECs have been evaluated, it is possible to compute the LCOL for the proposed schemes (Figure 19), by assuming three different electricity prices, that would represent a reasonable spread between wholesale market price, retail price and taxed retail price $(5-10-15 \mathrm{c} € / \mathrm{kWh})$.

For low energy prices, they are very similar: $7.5 \mathrm{c} € / \mathrm{kg}$ in all the cases except for AC-1 and AC-3, where it is $7 \mathrm{c} € / \mathrm{kg}$. This means that AC- 1 and AC-3 LCOL are lower by $6.5 \%$. For higher energy price LCOL in AC-1 $(13 \mathrm{c} € / \mathrm{kg})$ and AC-3 $(12.5 \mathrm{c} € / \mathrm{kg})$ is somewhat more convenient $(14 \%$ for AC-3) with respect to the base case $(14 \mathrm{c€} / \mathrm{kg})$. This is justified by a yearly reduction in energy consumption that weights more on LCOL when the energy price is high. With respect to the literature for a Linde cycle [36], the cost obtained is slightly lower: this difference is due to the different boundary conditions of this study, the different cycle layout adopted in this study, leading to lower specific consumption and the uncertainties of the boundary conditions. It is worth noticing that the order of magnitude of the specific cost achieved is the same as the literature.

To clarify these results, it could be useful to see that with 8400 equivalent hours of yearly production (the same value as in), $3500 \mathrm{t}$ of LNG are obtained. If the energy price is $5 \mathrm{c} € / \mathrm{kWh}$, the difference in yearly LCOL between the Base Case and the cheapest case (AC-3) is only $€ 17,500$. If the energy price is $15 \mathrm{c} € / \mathrm{kWh}$ the difference between the two cases is $€ 52,500$. These quantities may appear small, but in the context of a comparison 
between the two previous cases, it should be pointed out that CAPEX for AC-3 is just $€ 22,000$ higher than for the Base Case.

Anyway, real economic convenience should be carefully evaluated with detailed business plans considering all implications of these complex solutions.

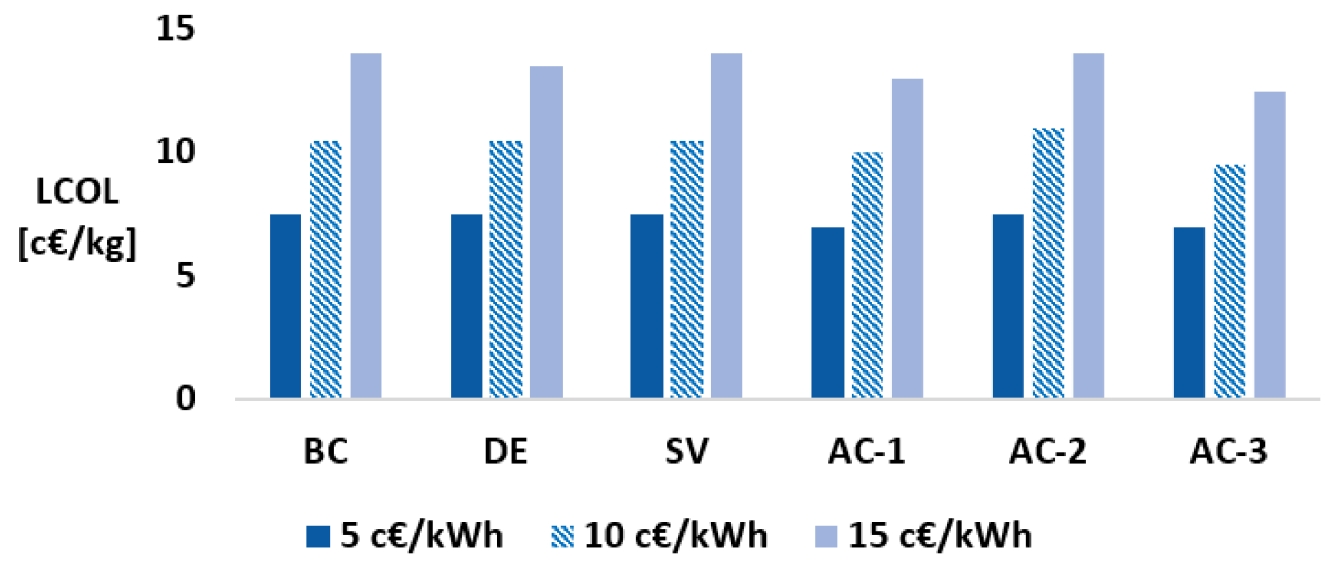

Figure 19. Levelized cost of liquefaction for the various cases. Different colors represent different price of energy.

\section{Conclusions}

Small-scale liquefaction plants are required for biomethane liquefaction directly at biogas production sites especially when biomethane grid injection is not feasible. Moreover, bio-LNG could be used for heavy transport decarbonization.

In this study, a techno-economic analysis of different "internal refrigerant" cycles (without additional refrigerant fluids) has been assessed with thermodynamic simulations using Aspen Hysys software. Also, the implementation of absorption chillers to recover waste thermal energy has been evaluated.

The base case (Kapitza Cycle) showed a specific consumption of $0.65 \mathrm{kWh} / \mathrm{kg}$ while simple modifications such as double pressure levels with additional valve or expander gave only negligible improvements (less than $2 \%$ in SV and DE). Absorption chillers, instead, led to better results, from $0.6 \mathrm{kWh} / \mathrm{kg}$ in AC-2 (-7.5\%) up to $0.54 \mathrm{kWh} / \mathrm{kg}(-17 \%)$ in the best configuration, $A C$-3. Even from a second law analysis point of view, best results occur with absorption chiller: they reduce the destruction of exergy in the intercoolers, providing a beneficial impact also in terms of reduction of energy losses in compressors (AC-2 and AC-3) and heat exchanges in the Cold Box (AC-1 and AC-3). The second law efficiency are $+16 \%,+8 \%$, and $+25 \%$ higher than the Base Case, respectively for AC-1, AC-2, and AC-3.

Regarding CapEx extimation, there is a $+11 \%$ gap, between the most economic solution (AC-1) and the most expensive one (AC-2). Due to the low cost of the absorption chiller systems, and their beneficial effects in reducing other equipment size, especially compressor power, higher performance doesn't mean higher costs. E.g., AC-1, has a lower cost and a lower specific consumption respect to the Base Case.

Hence, the Levelised Cost of Liquefaction was calculated for all cases and different electricity prices. LCOL variations for the proposed configurations are limited to roughly $1 \mathrm{c} € / \mathrm{kg}$, while the influence of electricity prices is more noticeable. Even if this difference may appear quite small, it could be significant when it is related to systems designed to work continuously throughout the year. Due to the reduced cost of the proposed modifications respect to the Base Case, these may recover quickly the initial investment and turn into profits.

It should be reminder however that this represent a prefeasibility study that should be confirmed by further assessment regarding the plant availability, reliability and part-load behavior, which might affect the feasibility of the proposed systems. 
Author Contributions: Conceptualization, A.B., G.P. and A.C.; methodology, A.B. and G.P.; software, A.C.; formal analysis, A.C.; data curation, A.C.; writing-original draft preparation, A.C. and G.P.; writing-review and editing, A.C., G.P., A.B., S.B. and L.F.; supervision S.B. and L.F. All authors have read and agreed to the published version of the manuscript.

Funding: This research received no external funding.

Conflicts of Interest: The authors declare no conflict of interest. The funders had no role in the design of the study; in the collection, analyses, or interpretation of data; in the writing of the manuscript, or in the decision to publish the results.

\section{Appendix A}

In the following tables are reported the main figures of several representative states of the cycles and power operation. The numbers of the streams refer to Figures 1-6. In the table related to operarating power the following nomenclature has been used:

$P_{\text {comp: }}$ compression power;

$P_{\text {exp: }}$ expansion power;

$P^{H}{ }_{\text {out }}$ : thermal power removed by air coolers

Table A1. States of the biomethane flows in the Base Case.

\begin{tabular}{lllll}
\hline Name & From Upgrading & $\mathbf{1}$ & $\mathbf{2}$ & $\mathbf{3}$ \\
\hline Temperature [C] & 30.0 & 39.8 & 177.5 & 49.1 \\
Pressure [bar] & 15.0 & 3.9 & 15.1 & 15.0 \\
Mass Flow [kg/h] & 417.0 & 1546.5 & 1546.5 & 1546.5 \\
\hline Name & $\mathbf{4}$ & $\mathbf{5}$ & $\mathbf{6}$ & $\mathbf{7}$ \\
\hline Temperature [C] & 124.5 & 45.0 & 122.6 & 45.0 \\
Pressure [bar] & 32.7 & 32.7 & 69.9 & 69.9 \\
Mass Flow [kg/h] & 1963.5 & 1963.5 & 1963.5 & 1963.5 \\
\hline Name & $\mathbf{8}$ & $\mathbf{9}$ & $\mathbf{1 0}$ & $\mathbf{1 1}$ \\
\hline Temperature [C] & 2.3 & 2.3 & -117.4 & -141.9 \\
Pressure [bar] & 69.8 & 69.8 & 69.8 & 4.0 \\
Mass Flow [kg/h] & 1963.5 & 526.0 & 526.0 & 526.0 \\
\hline Name & $\mathbf{1 3}$ & $\mathbf{1 4}$ & $\mathbf{1 5}$ & $\mathbf{1 6}$ \\
\hline Temperature [C] & -142.1 & -122.6 & 39.8 & 2.3 \\
Pressure [bar] & 4.0 & 4.0 & 3.9 & 69.8 \\
Mass Flow [kg/h] & 109.2 & 1546.7 & 1546.7 & 1437.5 \\
\hline Name & $\mathbf{1 7}$ & LNG & & \\
\hline Temperature [C] & -121.1 & -142.1 & & \\
Pressure [bar] & 4.0 & 4.0 & & \\
Mass Flow [kg/h] & 1437.5 & 416.8 & & \\
\hline & & & & \\
\hline
\end{tabular}

Table A2. This power data refer to operating unit in Base Case.

\begin{tabular}{ll}
\hline Component & Power \\
\hline C-1 & $\mathrm{P}_{\text {comp }}=145 \mathrm{~kW}$ \\
\hline $\mathrm{C}-2$ & $\mathrm{P}_{\text {comp }}=100 \mathrm{~kW}$ \\
\hline $\mathrm{C}-3$ & $\mathrm{P}_{\text {comp }}=100 \mathrm{~kW}$ \\
\hline $\mathrm{T}$ & $\mathrm{P}_{\text {exp }}=72 \mathrm{~kW}$ \\
\hline AC-1 & $\mathrm{P}_{\text {out }}^{\mathrm{H}}=140 \mathrm{~kW}$ \\
\hline AC-2 & $\mathrm{P}_{\text {out }}=110 \mathrm{~kW}$ \\
\hline AC-3 & $\mathrm{P}_{\text {out }}^{\mathrm{H}}=114 \mathrm{~kW}$ \\
\hline
\end{tabular}


Table A3. States of the biomethane flows in DE.

\begin{tabular}{|c|c|c|c|c|}
\hline Name & From Upgrading & $1 / 17$ & 2 & 3 \\
\hline Temperature [C] & 30.0 & 38.4 & 174.0 & 45.0 \\
\hline Pressure [bar] & 15.0 & 4.0 & 15.0 & 15.0 \\
\hline Mass Flow [kg/h] & 417.0 & 1548.7 & 1548.7 & 1548.7 \\
\hline Name & 4 & 5 & 6 & 7 \\
\hline Temperature [C] & 113.2 & 45.0 & 130.0 & 45.0 \\
\hline Pressure [bar] & 30.5 & 30.4 & 69.9 & 69.9 \\
\hline Mass Flow $[\mathrm{kg} / \mathrm{h}]$ & 1965.7 & 1965.7 & 1965.7 & 1965.7 \\
\hline Name & 8 & 9 & 10 & 11 \\
\hline Temperature [C] & 45.0 & -9.7 & -9.7 & -124.3 \\
\hline Pressure [bar] & 69.9 & 69.8 & 69.8 & 69.8 \\
\hline Mass Flow $[\mathrm{kg} / \mathrm{h}]$ & 1654.5 & 1654.5 & 490.0 & 490.0 \\
\hline Name & 12 & 14 & 15 & 16 \\
\hline Temperature [C] & -141.7 & -141.9 & -131.4 & 40.0 \\
\hline Pressure [bar] & 4.1 & 4.0 & 4.0 & 4.0 \\
\hline Mass Flow $[\mathrm{kg} / \mathrm{h}]$ & 490.0 & 73.0 & 1237.5 & 1237.5 \\
\hline Name & 18 & 19 & 20 & 21 \\
\hline Temperature [C] & 45.0 & -87.6 & 32.0 & -9.7 \\
\hline Pressure [bar] & 69.9 & 4.0 & 4.0 & 69.8 \\
\hline Mass Flow $[\mathrm{kg} / \mathrm{h}]$ & 311.2 & 311.2 & 311.2 & 1164.5 \\
\hline Name & 22 & LNG & & \\
\hline Temperature [C] & -130.7 & -141.9 & & \\
\hline Pressure [bar] & 4.0 & 4.0 & & \\
\hline Mass Flow $[\mathrm{kg} / \mathrm{h}]$ & 1164.5 & 417.0 & & \\
\hline
\end{tabular}

Table A4. This power data refer to operating unit in DE.

\begin{tabular}{ll}
\hline Component & Power \\
\hline C-1 & $\mathrm{P}_{\text {comp }}=143 \mathrm{~kW}$ \\
\hline C-2 & $\mathrm{P}_{\text {comp }}=91 \mathrm{~kW}$ \\
\hline $\mathrm{C}-3$ & $\mathrm{P}_{\text {comp }}=105 \mathrm{~kW}$ \\
\hline $\mathrm{T}-1$ & $\mathrm{P}_{\text {exp }}=20 \mathrm{~kW}$ \\
\hline T-2 & $\mathrm{P}_{\text {exp }}=54 \mathrm{~kW}$ \\
\hline AC-1 & $\mathrm{P}_{\text {out }}^{\mathrm{H}}=141 \mathrm{~kW}$ \\
\hline AC-2 & $\mathrm{P}_{\text {out }}^{\mathrm{H}}=94 \mathrm{~kW}$ \\
\hline AC-3 & $\mathrm{P}_{\text {out }}^{\mathrm{H}}=126 \mathrm{~kW}$ \\
\hline
\end{tabular}

Table A5. States of the biomethane flows in SV.

\begin{tabular}{|c|c|c|c|c|}
\hline Name & 1 & 2 & 3 & 4 \\
\hline Temperature [C] & 39.6 & 175.5 & 45.0 & 121.5 \\
\hline Pressure [bar] & 4.0 & 15.0 & 15.0 & 33.0 \\
\hline Mass Flow $[\mathrm{kg} / \mathrm{h}]$ & 1562.4 & 1562.4 & 1562.4 & 1979.4 \\
\hline Name & 5 & 6 & 7 & 8 \\
\hline Temperature [C] & 45.0 & 121.6 & 45.0 & 3.3 \\
\hline Pressure [bar] & 33.0 & 70.0 & 69.9 & 69.9 \\
\hline Mass Flow $[\mathrm{kg} / \mathrm{h}]$ & 1979.4 & 1979.4 & 1979.4 & 1979.4 \\
\hline Name & 9 & 10 & 11 & 12 \\
\hline Temperature [C] & 3.3 & -113.9 & -113.9 & -130.8 \\
\hline Pressure [bar] & 69.9 & 69.8 & 69.8 & 69.8 \\
\hline Mass Flow $[\mathrm{kg} / \mathrm{h}]$ & 546.8 & 546.8 & 461.6 & 461.6 \\
\hline Name & 13 & 15 & 16 & 17 \\
\hline Temperature [C] & -141.7 & -141.9 & 36.1 & 3.3 \\
\hline Pressure [bar] & 4.1 & 4.0 & 4.0 & 69.9 \\
\hline Mass Flow $[\mathrm{kg} / \mathrm{h}]$ & 461.6 & 44.6 & 44.6 & 1432.6 \\
\hline Name & 18 & 19 & 20 & 21 \\
\hline Temperature [C] & -120.0 & 39.9 & -113.9 & -141.9 \\
\hline Pressure [bar] & 4.0 & 4.0 & 69.8 & 4.0 \\
\hline Mass Flow $[\mathrm{kg} / \mathrm{h}]$ & 1432.6 & 1432.6 & 85.2 & 85.2 \\
\hline Name & 22 & LNG & From upgrading & \\
\hline Temperature [C] & 35.5 & -141.9 & 30.0 & \\
\hline Pressure [bar] & 4.0 & 4.0 & 15.0 & \\
\hline Mass Flow $[\mathrm{kg} / \mathrm{h}]$ & 85.2 & 417.0 & 417.0 & \\
\hline
\end{tabular}


Table A6. This power data refer to operating unit in SV.

\begin{tabular}{ll}
\hline Component & Power \\
\hline C-1 & $\mathrm{P}_{\text {comp }}=145 \mathrm{~kW}$ \\
\hline $\mathrm{C}-2$ & $\mathrm{P}_{\text {comp }}=101 \mathrm{~kW}$ \\
\hline $\mathrm{C}-3$ & $\mathrm{P}_{\text {comp }}=95 \mathrm{~kW}$ \\
\hline $\mathrm{T}$ & $\mathrm{P}_{\text {exp }}=72 \mathrm{~kW}$ \\
\hline AC-1 & $\mathrm{P}_{\text {out }}^{\mathrm{H}}=144 \mathrm{~kW}$ \\
\hline AC-2 & $\mathrm{P}^{\mathrm{H}}$ out $=107 \mathrm{~kW}$ \\
\hline AC-3 & $\mathrm{P}_{\text {out }}^{\mathrm{H}}=114 \mathrm{~kW}$ \\
\hline
\end{tabular}

Table A7. States of the biomethane flows in AC-1.

\begin{tabular}{lllll}
\hline Name & From Upgrading & $\mathbf{1}$ & $\mathbf{2}$ & $\mathbf{3}$ \\
\hline Temperature [C] & 30.0 & 3.7 & 131.0 & 111.0 \\
Pressure [bar] & 15.0 & 4.0 & 15.0 & 15.0 \\
Mass Flow [kg/h] & 417.0 & 1472.2 & 1472.2 & 1472.2 \\
\hline Name & $\mathbf{4}$ & $\mathbf{5}$ & $\mathbf{6}$ & $\mathbf{7}$ \\
\hline Temperature [C] & 45.0 & 115.4 & 100.2 & 45.0 \\
Pressure [bar] & 14.9 & 31.1 & 31.0 & 31.0 \\
Mass Flow [kg/h] & 1472.2 & 1889.2 & 1889.2 & 1889.2 \\
\hline Name & $\mathbf{8}$ & $\mathbf{9}$ & $\mathbf{1 0}$ & $\mathbf{1 1}$ \\
\hline Temperature [C] & 121.2 & 105.1 & 45.0 & 13.4 \\
Pressure [bar] & 65.5 & 65.5 & 65.4 & 65.4 \\
Mass Flow [kg/h] & 1889.2 & 1889.2 & 1889.2 & 1889.2 \\
\hline Name & $\mathbf{1 2}$ & $\mathbf{1 3}$ & $\mathbf{1 4}$ & $\mathbf{1 5}$ \\
\hline Temperature [C] & -9.5 & -9.5 & -120.0 & -141.7 \\
Pressure [bar] & 65.3 & 65.3 & 65.3 & 4.1 \\
Mass Flow [kg/h] & 1889.2 & 510.9 & 510.9 & 510.9 \\
\hline Name & $\mathbf{1 7}$ & $\mathbf{1 8}$ & $\mathbf{1 9}$ & $\mathbf{2 0}$ \\
\hline Temperature [C] & -141.9 & 4.1 & -9.5 & -127.4 \\
Pressure [bar] & 4.0 & 4.0 & 65.3 & 4.0 \\
Mass Flow [kg/h] & 93.9 & 93.9 & 1378.3 & 1378.3 \\
Name & $\mathbf{2 1}$ & $\mathbf{L N G}$ & & \\
\hline Temperature [C] & 3.6 & -141.9 & & \\
Pressure [bar] & 4.0 & 4.0 & & \\
Mass Flow [kg/h] & 1378.3 & 417.0 & & \\
\hline & & & & \\
\hline
\end{tabular}

Table A8. States of the water flows in AC-1.

\begin{tabular}{lllll}
\hline Name & A3 & A4 & A6 & A7 \\
\hline Temperature [C] & 83.0 & 90.0 & 83.0 & 90.0 \\
Pressure $[\mathrm{bar}]$ & 2.0 & 2.0 & 2.0 & 2.0 \\
Mass Flow $[\mathrm{kg} / \mathrm{h}]$ & 2459.6 & 2459.6 & 2431.7 & 2431.7 \\
\hline Name & $\mathbf{A 9}$ & $\mathbf{A 1 0}$ & $\mathbf{A 1 3}$ & $\mathbf{A 1 4}$ \\
\hline Temperature [C] & 83.0 & 90.0 & 7.0 & 15.0 \\
Pressure $[\mathrm{bar}]$ & 2.0 & 2.0 & 2.0 & 1.9 \\
Mass Flow $[\mathrm{kg} / \mathrm{h}]$ & 2688.0 & 2688.0 & 4696.9 & 4696.9 \\
\hline
\end{tabular}


Table A9. This power data refer to operating unit in AC-1.

\begin{tabular}{ll}
\hline Component & Power \\
\hline C-1 & $\mathrm{P}_{\text {comp }}=145 \mathrm{~kW}$ \\
\hline $\mathrm{C}-2$ & $\mathrm{P}_{\text {comp }}=101 \mathrm{~kW}$ \\
\hline $\mathrm{C}-3$ & $\mathrm{P}_{\text {comp }}=95 \mathrm{~kW}$ \\
\hline $\mathrm{T}$ & $\mathrm{P}_{\text {exp }}=72 \mathrm{~kW}$ \\
\hline AC-1 & $\mathrm{P}_{\text {out }}^{\mathrm{H}}=144 \mathrm{~kW}$ \\
\hline AC-2 & $\mathrm{P}_{\text {out }}^{\mathrm{H}}=107 \mathrm{~kW}$ \\
\hline AC-3 & $\mathrm{P}^{\mathrm{H}}$ out $=114 \mathrm{~kW}$ \\
\hline
\end{tabular}

Table A10. States of the biomethane flows in AC-2.

\begin{tabular}{lllll}
\hline Name & From Upgrading & $\mathbf{1}$ & $\mathbf{2}$ & $\mathbf{3}$ \\
\hline Temperature [C] & 30.0 & 40.0 & 17.0 & 149.0 \\
Pressure [bar] & 15.0 & 4.0 & 3.9 & 15.0 \\
Mass Flow [kg/h] & 417.0 & 1600.7 & 1600.7 & 1600.7 \\
\hline Name & $\mathbf{4}$ & $\mathbf{5}$ & $\mathbf{6}$ & $\mathbf{7}$ \\
\hline Temperature [C] & 90.1 & 45.0 & 24.9 & 100.9 \\
Pressure [bar] & 15.0 & 14.9 & 14.9 & 32.4 \\
Mass Flow [kg/h] & 1600.7 & 1600.7 & 2017.7 & 2017.7 \\
\hline Name & $\mathbf{8}$ & $\mathbf{9}$ & $\mathbf{1 0}$ & $\mathbf{1 1}$ \\
\hline Temperature [C] & 89.5 & 45.0 & 28.9 & 100.5 \\
Pressure [bar] & 32.3 & 32.3 & 32.2 & 66.6 \\
Mass Flow [kg/h] & 2017.7 & 2017.7 & 2017.7 & 2017.7 \\
\hline Name & $\mathbf{1 2}$ & $\mathbf{1 3}$ & $\mathbf{1 4}$ & $\mathbf{1 5}$ \\
\hline Temperature [C] & 91.6 & 45.0 & -1.6 & -1.6 \\
Pressure [bar] & 66.6 & 66.5 & 66.5 & 66.5 \\
Mass Flow [kg/h] & 2017.7 & 2017.7 & 2017.7 & 519.9 \\
\hline Name & $\mathbf{1 6}$ & $\mathbf{1 7}$ & $\mathbf{1 8}$ & $\mathbf{1 9}$ \\
\hline Temperature [C] & -118.3 & -141.7 & -141.9 & -141.9 \\
Pressure [bar] & 66.4 & 4.1 & 4.0 & 4.0 \\
Mass Flow [kg/h] & 519.9 & 519.9 & 417.0 & 102.9 \\
Name & $\mathbf{2 0}$ & $\mathbf{2 1}$ & $\mathbf{2 2}$ & $\mathbf{2 3}$ \\
\hline Temperature [C] & 40.0 & -1.6 & -121.7 & 40.0 \\
Pressure [bar] & 4.0 & 66.5 & 4.0 & 4.0 \\
Mass Flow [kg/h] & 102.9 & 1497.9 & 1497.9 & 1497.9 \\
\hline
\end{tabular}

Table A11. States of the water flows in AC-2.

\begin{tabular}{lllll}
\hline Name & A4 & A5 & A6 & A7 \\
\hline Temperature $[\mathrm{C}]$ & 83.0 & 90.0 & 83.0 & 90.0 \\
Pressure $[\mathrm{bar}]$ & 2.0 & 2.0 & 2.0 & 2.0 \\
Mass Flow $[\mathrm{kg} / \mathrm{h}]$ & 7898.7 & 7898.7 & 1918.0 & 1918.0 \\
\hline Name & $\mathbf{A 9}$ & $\mathbf{A 1 0}$ & $\mathbf{A 1 5}$ & $\mathbf{A 1 6}$ \\
\hline Temperature $[\mathrm{C}]$ & 83.0 & 90.0 & 7.0 & 15.0 \\
Pressure $[\mathrm{bar}]$ & 2.0 & 2.0 & 2.0 & 1.9 \\
Mass Flow $[\mathrm{kg} / \mathrm{h}]$ & 1581.5 & 1581.5 & 2418.5 & 2418.5 \\
\hline Name & $\mathbf{A 1 7}$ & $\mathbf{A 1 8}$ & $\mathbf{A 2 0}$ & $\mathbf{A 2 1}$ \\
\hline Temperature $[\mathrm{C}]$ & 7.0 & 15.0 & 7.0 & 15.0 \\
Pressure $[\mathrm{bar}]$ & 2.0 & 1.9 & 2.0 & 1.9 \\
Mass Flow $[\mathrm{kg} / \mathrm{h}]$ & 2331.7 & 2331.7 & 2313.2 & 2313.2 \\
\hline
\end{tabular}


Table A12. This power data refer to operating unit in AC-2.

\begin{tabular}{ll}
\hline Component & Power \\
\hline C-1 & $\mathrm{P}_{\text {comp }}=140 \mathrm{~kW}$ \\
\hline $\mathrm{C}-2$ & $\mathrm{P}_{\text {comp }}=\mathrm{kW}$ \\
\hline $\mathrm{C}-3$ & $\mathrm{P}_{\text {comp }}=95 \mathrm{~kW}$ \\
\hline $\mathrm{T}$ & $\mathrm{P}_{\text {exp }}=90 \mathrm{~kW}$ \\
\hline AC-1 & $\mathrm{P}_{\text {out }}^{\mathrm{H}}=48 \mathrm{~kW}$ \\
\hline AC-2 & $\mathrm{P}_{\text {out }}^{\mathrm{H}}=62 \mathrm{~kW}$ \\
\hline AC-3 & $\mathrm{P}^{\mathrm{H}}$ out $=70 \mathrm{~kW}$ \\
\hline
\end{tabular}

Table A13. States of the biomethane flows in AC-3.

\begin{tabular}{|c|c|c|c|c|}
\hline Name & From Upgrading & 1 & 2 & 3 \\
\hline Temperature [C] & 30.0 & 6.0 & 134.0 & 89.7 \\
\hline Pressure [bar] & 15.0 & 4.0 & 15.0 & 15.0 \\
\hline Mass Flow $[\mathrm{kg} / \mathrm{h}]$ & 417.0 & 1357.9 & 1357.9 & 1357.9 \\
\hline Name & 4 & 5 & 6 & 7 \\
\hline Temperature [C] & 45.0 & 32.6 & 112.7 & 89.0 \\
\hline Pressure [bar] & 14.9 & 14.9 & 33.3 & 3328.0 \\
\hline Mass Flow $[\mathrm{kg} / \mathrm{h}]$ & 1357.9 & 1774.9 & 1774.9 & 1774.9 \\
\hline Name & 8 & 9 & 10 & 11 \\
\hline Temperature [C] & 45.0 & 34.7 & 107.4 & 88.7 \\
\hline Pressure [bar] & 33.2 & 33.2 & 68.7 & 68.7 \\
\hline Mass Flow $[\mathrm{kg} / \mathrm{h}]$ & 1774.9 & 1774.9 & 1774.9 & 1774.9 \\
\hline Name & 12 & 13 & 14 & 15 \\
\hline Temperature [C] & 45.0 & 11.6 & -12.0 & -12.0 \\
\hline Pressure [bar] & 68.6 & 68.6 & 68.5 & 68.5 \\
\hline Mass Flow $[\mathrm{kg} / \mathrm{h}]$ & 1774.9 & 1774.9 & 1774.9 & 479.7 \\
\hline Name & 16 & 17 & 18 & 19 \\
\hline Temperature [C] & -126.5 & -141.7 & -141.9 & -141.9 \\
\hline Pressure [bar] & 68.5 & 4.1 & 4.0 & 4.0 \\
\hline Mass Flow $[\mathrm{kg} / \mathrm{h}]$ & 479.7 & 479.7 & 417.0 & 62.7 \\
\hline Name & 20 & 21 & 22 & 23 \\
\hline Temperature [C] & 3.9 & -12.0 & -131.8 & 6.1 \\
\hline Pressure [bar] & 4.0 & 68.5 & 4.0 & 4.0 \\
\hline Mass Flow $[\mathrm{kg} / \mathrm{h}]$ & 62.7 & 1295.2 & 1295.2 & 1295.2 \\
\hline
\end{tabular}

Table A14. States of the water flows in AC-3.

\begin{tabular}{lllll}
\hline Name & A4 & A5 & A6 & A7 \\
\hline Temperature $[\mathrm{C}]$ & 83.0 & 90.0 & 83.0 & 90.0 \\
Pressure $[\mathrm{bar}]$ & 2.0 & 2.0 & 2.0 & 2.0 \\
Mass Flow $[\mathrm{kg} / \mathrm{h}]$ & 4988.7 & 4988.7 & 3536.9 & 3536.9 \\
\hline Name & $\mathbf{A 9}$ & $\mathbf{A 1 0}$ & $\mathbf{A 1 5}$ & $\mathbf{A 1 6}$ \\
\hline Temperature $[\mathrm{C}]$ & 83.0 & 90.0 & 7.0 & 15.0 \\
Pressure $[\mathrm{bar}]$ & 2.0 & 2.0 & 2.0 & 1.9 \\
Mass Flow $[\mathrm{kg} / \mathrm{h}]$ & 2933.2 & 2933.2 & 1072.9 & 1072.9 \\
\hline Name & $\mathbf{A 1 7}$ & $\mathbf{A 1 8}$ & $\mathbf{A 2 0}$ & $\mathbf{A 2 1}$ \\
\hline Temperature $[\mathrm{C}]$ & 7.0 & 15.0 & 7.0 & 15.0 \\
Pressure $[\mathrm{bar}]$ & 2.0 & 1.9 & 2.0 & 1.9 \\
Mass Flow $[\mathrm{kg} / \mathrm{h}]$ & 1305.1 & 1305.1 & 4722.9 & 4722.9 \\
\hline
\end{tabular}


Table A15. This power data refer to operating unit in AC-3.

\begin{tabular}{ll}
\hline Component & Power \\
\hline$C-1$ & $\mathrm{P}_{\text {comp }}=112 \mathrm{~kW}$ \\
\hline$C-2$ & $\mathrm{P}_{\text {comp }}=87 \mathrm{~kW}$ \\
\hline $\mathrm{C}-3$ & $\mathrm{P}_{\text {comp }}=80 \mathrm{~kW}$ \\
\hline $\mathrm{T}$ & $\mathrm{P}_{\text {exp }}=58 \mathrm{~kW}$ \\
\hline AC-1 & $\mathrm{P}_{\text {out }}^{\mathrm{H}}=41 \mathrm{~kW}$ \\
\hline AC-2 & $\mathrm{P}_{\text {out }}^{\mathrm{H}}=54 \mathrm{~kW}$ \\
\hline AC-3 & $\mathrm{P}_{\text {out }}^{\mathrm{H}}=58 \mathrm{~kW}$ \\
\hline
\end{tabular}

\section{References}

1. Pasini, G.; Baccioli, A.; Ferrari, L.; Antonelli, M.; Frigo, S.; Desideri, U. Biomethane grid injection or biomethane liquefaction: A technical-economic analysis. Biomass Bioenergy 2019, 127, 105264. [CrossRef]

2. Request for Proposals Feasibility Study for the Micro-Scale Lng Plants Project in Mexico 2020. Available online: https://ustda. gov/business_opp_oversea/mexico-feasibility-study-micro-scale-lng-plants/ (accessed on 15 February 2021).

3. Blades, L.; Morgan, K.; Douglas, R.; Glover, S.; De Rosa, M.; Cromie, T.; Smyth, B. Circular Biogas-Based Economy in a Rural Agricultural Setting. Energy Procedia 2017, 123, 89-96. [CrossRef]

4. Lillo, P.; Ferrer-Martí, L.; Fernández-Baldor, Á.; Ramírez, B. A new integral management model and evaluation method to enhance sustainability of renewable energy projects for energy and sanitation services. Energy Sustain. Dev. 2015, 29, 1-12. [CrossRef]

5. Pöschl, M.; Ward, S.; Owende, P. Evaluation of energy efficiency of various biogas production and utilization pathways. Appl. Energy 2010, 87, 3305-3321. [CrossRef]

6. Baccioli, A.; Ferrari, L.; Vizza, F.; Desideri, U. Feasibility analysis of coupling an ORC to a mGT in a biogas plant. Energy Procedia 2019, 158, 2311-2316. [CrossRef]

7. Kunz, A. Strategic Integration of Biomethane in the Gas Grid. 2017. Available online: https://www.ieabioenergy.com/wpcontent/uploads/2017/10/5_Strategic-Integration-of-Biomethane_A.Kunz_pdf (accessed on 21 February 2019).

8. Cucchiella, F.; D'Adamo, I.; Gastaldi, M. Profitability analysis for biomethane: A strategic role in the Italian transport sector. Int. J. Energy Econ. Policy 2015, 5, 440-449.

9. Petersson, A.; Wellinger, A. Biogas Upgrading Technologies-Developments and Innovations Task 37-Energy from Biogas and Landfill Gas. 2009. Available online: https://www.ieabioenergy.com/wp-content/uploads/2009/10/upgrading_rz_low_final.pdf (accessed on 1 May 2021).

10. Sun, Q.; Li, H.; Yan, J.; Liu, L.; Yu, Z.; Yu, X. Selection of appropriate biogas upgrading technology-a review of biogas cleaning, upgrading and utilisation. Renew. Sustain. Energy Rev. 2015, 51, 521-532. [CrossRef]

11. Baccioli, A.; Antonelli, M.; Frigo, S.; Desideri, U.; Pasini, G. Small scale bio-LNG plant: Comparison of different biogas upgrading techniques. Appl. Energy 2018, 217, 328-335. [CrossRef]

12. Mazyan, W.; Ahmadi, A.; Ahmed, H.; Hoorfar, M. Market and technology assessment of natural gas processing: A review. J. Nat. Gas Sci. Eng. 2016, 30, 487-514. [CrossRef]

13. Castillo, L.; Dorao, C. Influence of the plot area in an economical analysis for selecting small scale LNG technologies for remote gas production. J. Nat. Gas Sci. Eng. 2010, 2, 302-309. [CrossRef]

14. Rehman, A.; Qyyum, M.A.; Ahmad, A.; Nawaz, S.; Lee, M.; Wang, L. Performance Enhancement of Nitrogen Dual Expander and Single Mixed Refrigerant LNG Processes Using Jaya Optimization Approach. Energies 2020, 13, 3278. [CrossRef]

15. Wang, X.; Li, M.; Cai, L.; Li, Y. Propane and iso-butane pre-cooled mixed refrigerant liquefaction process for small-scale skid-mounted natural gas liquefaction. Appl. Energy 2020, 275, 115333. [CrossRef]

16. Park, J.; In, S.; Ko, J.; Kim, H.; Hong, Y.; Yeom, H.; Park, S. Development of a kw-class Stirling cryocooler for liquefaction of natural gas (NG). IOP Conf. Ser. Mater. Sci. Eng. 2020, 755, 012035. [CrossRef]

17. Lee, K.; Koh, D.-Y.; Ko, J.; Yeom, H.; Son, C.-H.; Yoon, J.-I. Design and Performance Test of 2 kW Class Reverse Brayton Cryogenic System. Energies 2020, 13, 5089. [CrossRef]

18. Lunkova, L.G.; Melnikov, G.S.; Gulkov, A.N.; Lapshin, V.D. The Natural Gas Liquefaction Technology for Small-Scale LNG. IOP Conf. Ser. Earth Environ. Sci. 2020, 459, 052094. [CrossRef]

19. Khan, M.S.; Lee, S.; Getu, M.; Lee, M. Knowledge inspired investigation of selected parameters on energy consumption in nitrogen single and dual expander processes of natural gas liquefaction. J. Nat. Gas Sci. Eng. 2015, 23, 324-337. [CrossRef]

20. Qyyum, M.A.; Wei, F.; Hussain, A.; Noon, A.A.; Lee, M. An innovative vortex-tube turbo-expander refrigeration cycle for performance enhancement of nitrogen-based natural-gas liquefaction process. Appl. Therm. Eng. 2018, 144, 117-125. [CrossRef]

21. Dhillon, A.K.; Ghosh, P. Performance characteristics map using exergy analysis of reverse Brayton cryocooler for HTS applications: Selection, Optimization, Design and Operational guidelines. Cryogenics 2020, 106, 103024. [CrossRef] 
22. Kochunni, S.K.; Chowdhury, K. Zero methane loss in reliquefaction of boil-off gas in liquefied natural gas carrier ships by using packed bed distillation in reverse Brayton system. J. Clean. Prod. 2020, 260, 121037. [CrossRef]

23. Kochunni, S.K.; Chowdhury, K. Essential design criteria for safe and efficient operation of an LNG boil-off gas reliquefier under deteriorated performance of system components. Cryogenics 2021, 120, 103371. [CrossRef]

24. He, T.; Lin, W. Energy saving and production increase of mixed refrigerant natural gas liquefaction plants by taking advantage of natural cold sources in winter. J. Clean. Prod. 2021, 299, 126884. [CrossRef]

25. Gómez, J.R.; Garcia, R.F.; Catoira, A.D.M. On board LNG reliquefaction technology: A comparative study. Pol. Marit. Res. 2013, 21, 77-88. [CrossRef]

26. Kochunni, S.K.; Chowdhury, K. LNG boil-off gas reliquefaction by Brayton refrigeration system-Part 1: Exergy analysis and design of the basic configuration. Energy 2019, 176, 753-764. [CrossRef]

27. He, T.; Qyyum, M.A.; Zhou, Z.; Ahmad, A.; Rehan, M.; Nizami, A.-S.; Lee, M. Black Hole-Inspired Optimal Design of Biomethane Liquefaction Process for Small-Scale Applications. Front. Energy Res. 2021, 9, 100. [CrossRef]

28. Wärtsilä Biogas Solutions. Available online: https://www.wartsila.com/marine/build/gas-solutions/biogas-solutions (accessed on 26 October 2021).

29. Wang, H.; Chen, G.; Dong, X.; Zhao, Y.; Guo, H.; Gong, M. Performance comparison of single-stage mixed-refrigerant JouleThomson cycle and pure-gas reverse Brayton cycle at fixed-temperatures from 80 to $180 \mathrm{~K}$. Int. J. Refrig. 2017, 80, 77-91. [CrossRef]

30. Kerry, F.G. Industrial Gas Handbook: Gas Separation and Purification; CRC Press: Boca Raton, FL, USA, 2007 ; ISBN 9781420008265.

31. Hamdy, S.; Moser, F.; Morosuk, T.; Tsatsaronis, G. Exergy-Based and Economic Evaluation of Liquefaction Processes for Cryogenics Energy Storage. Energies 2019, 12, 493. [CrossRef]

32. Capra, F.; Magli, F.; Gatti, M. Biomethane liquefaction: A systematic comparative analysis of refrigeration technologies Appl. Therm. Eng. 2019, 158, 113815. [CrossRef]

33. Ancona, M.; Bianchi, M.; Branchini, L.; De Pascale, A.; Melino, F. Performance Increase of a Small-scale Liquefied Natural Gas Production Process by Means of Turbo-expander. Energy Procedia 2017, 105, 4859-4865. [CrossRef]

34. Kochunni, S.K.; Chowdhury, K. Comparison between reverse Brayton and Kapitza basedLNG boil-off gas reliquefaction system using exergy analysis. IOP Conf. Ser. Mater. Sci. Eng. 2017, 171, 012009. [CrossRef]

35. Spoof-tuomi, K. “Techno-Economic Analysis of Biomethane Liquefaction Processes," no November, pp. 1-45. 2020. Available online: https://www.uwasa.fi/sites/default/files/2020-12/Techno_economic_analysis_of_biomethane_liquefaction_processes.pdf (accessed on 1 March 2021).

36. Zhang, J.; Meerman, H.; Benders, R.; Faaij, A. Technical and economic optimization of expander-based small-scale natural gas liquefaction processes with absorption precooling cycle. Energy 2020, 191, 116592. [CrossRef]

37. Peng, D.-Y.; Robinson, D.B. A New Two-Constant Equation of State. Ind. Eng. Chem. Fundam. 1976, 15, 59-64. [CrossRef]

38. Our plant-GM Green Methane. Available online: https:/ / www.greenmethane.it/en-us/plant (accessed on 1 January 2021).

39. Aspen HYSYSIProcess Simulation Software/AspenTech. Available online: https://www.aspentech.com/en/products/ engineering/aspen-hysys (accessed on 11 January 2021).

40. Baccioli, A.; Antonelli, M.; Desideri, U. Dynamic modeling of a solar ORC with compound parabolic collectors: Annual production and comparison with steady-state simulation. Energy Convers. Manag. 2017, 148, 708-723. [CrossRef]

41. Maya Air Conditioning Assorbitori. Available online: http://www.maya-airconditioning.com/ (accessed on 15 June 2018).

42. IEA PVPS Task 13. Uncertainty in Yield Assessment and PV LCOE, ISBN 9783907281062. 2020. Available online: https:/ / iea-pvps.org/wp-content/uploads/2021/01/Report-IEA\%E2\%80\%93PVPS-T13-18_2020-Uncertainties-in-YieldAssessments-and-PV-LCOE-1.pdf (accessed on 15 November 2021).

43. Turton, R.; Bailie, R.C.; Whiting, W.B.; Shaeiwitz, J.A.; Bhattacharyya, D. Analysis, Synthesis, and Design of Chemical Processes, 4th ed.; Pearson, Ed.; Prentice Hall: Hoboken, NJ, USA, 2012; ISBN 9780132940290. 